\title{
Human Polycystin-2 Transgene Dose-Dependently Rescues ADPKD Phenotypes in Pkd2 Mutant Mice
}

\author{
Ao Li, ${ }^{*}$ Xin Tian, ${ }^{\dagger}$ Xiaoli Zhang, ${ }^{*}$ Shunwei Huang,${ }^{\ddagger}$ Yujie Ma, ${ }^{*}$ Dianqing Wu, ${ }^{\S}$ Gilbert Moeckel,,${ }^{\llbracket}$ Stefan Somlo, ${ }^{\dagger}$ and \\ Guanqing $W u^{*} \stackrel{\sharp}{*}$
}

\begin{abstract}
From the Center of Translational Cancer Research and Therapy, * State Key Laboratory of Molecular Oncology, Cancer Hospital and Institute, Chinese Academy of Medical Sciences and Peking Union Medical College, Beijing, China; the Departments of Internal Medicine, ${ }^{\dagger}$ Pharmacology, ${ }^{\S}$ Pathology, ${ }^{\uparrow}$ Yale University School of Medicine, New Haven, Connecticut; and the Department of Medicine, ${ }^{\ddagger}$ Vanderbilt University, Nashville, Tennessee
\end{abstract}

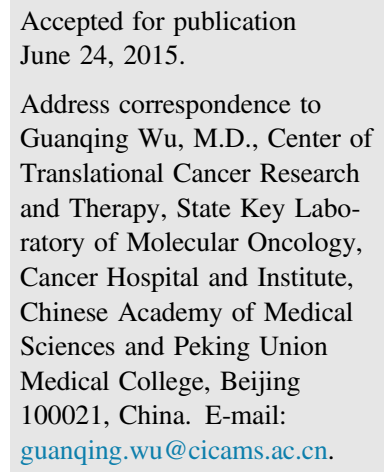

\begin{abstract}
Although much is known about the molecular genetic mechanisms of autosomal-dominant polycystic kidney disease (ADPKD), few effective treatment is currently available. Here, we explore the in vivo effects of causal gene replacement in orthologous gene models of ADPKD in mice. Wild-type mice with human PKD2 transgene ( $P K D 2^{\mathrm{tg}}$ ) overexpressed polycystin (PC)-2 in several tissues, including the kidney and liver, and showed no significant cyst formation in either organ. We cross-mated $P K D 2^{\text {tg }}$ with a $P k d 2$ null mouse model, which is embryonically lethal and forms renal and pancreatic cysts. $P k d 2^{-/-}$mice with human $P K D 2$ transgene $\left(P k d 2^{-{ }^{-}} ; P K D 2^{\mathrm{tg}}\right)$ were born in expected Mendelian ratios, indicating that the embryonic lethality of the $P k d 2^{-/-}$mice was rescued. $P k d 2^{-/-} ; P K D 2^{\text {tg }}$ mice survived up to 12 months and exhibited moderate to severe cystic phenotypes of the kidney, liver, and pancreas. Moreover, $P k d 2^{-/-}$mice with homozygous $P K D 2^{\mathrm{tg}}$-transgene alleles $\left(P k d 2^{-/-} ; P K D 2^{\mathrm{tg} / \mathrm{tg}}\right)$ showed significant further amelioration of the cystic severity compared to that in $P k d 2^{-/-}$mice with a hemizygous $P K D 2^{\text {tg }}$ allele $\left(P k d 2^{-/-} ; P K D 2^{\text {tg }}\right)$, suggesting that the ADPKD phenotype was improved by increased transgene dosage. On further analysis, cystic improvement mainly resulted from reduced proliferation, rather apoptosis, of cyst-prone epithelial cells in the mouse model. The finding that the functional restoration of human PC2 significantly rescued ADPKD phenotypes in a dose-dependent manner suggests that increasing PC2 activity may be beneficial in some forms of ADPKD. (Am J Pathol 2015, 185: 2843-2860; http://dx.doi.org/10.1016/j.ajpath.2015.06.014)
\end{abstract}

Autosomal-dominant polycystic kidney disease (ADPKD) is a common, inherited monogenic disease resulting from mutations in either $P K D 1$ or $P K D 2 .^{1,2}$ Besides numerous progressive, bilateral, fluid-filled cysts in the kidneys derived from renal tubular epithelial cells, ADPKD patients also have very eminent extrarenal manifestations. ${ }^{3,4}$ The most common extrarenal manifestation is bile duct-derived cyst formation in the liver. ${ }^{3-6}$ Hepatic cysts occur in $83 \%$ of all ADPKD patients, and in $94 \%$ of those aged $\geq 35$ years. $^{7,8}$ Other phenotypes include pancreatic cysts, cerebrovascular aneurysm, ${ }^{10,11}$ and aortic root/thoracic aorta abnormalities. $^{12,13}$

ADPKD usually develops in early adulthood, with an incidence of $1: 400$ to $1: 1000$. It is the fourth most common cause of end-stage renal disease, which occurs in $50 \%$ of affected individuals by age 60 years. ${ }^{14}$ The cyst formation in ADPKD is thought to occur largely by a cellular recessive somatic second-hit mechanism, ${ }^{15,16}$ although other factors, such as the timing of second-step mutations, ${ }^{17}$ kidney injury, ${ }^{18}$ and inflammation, ${ }^{19}$ as well as allelism with the nonmutant chromosome, ${ }^{20}$ likely significantly influence disease progression as well.

Supported by the National 973 Program (2012CB517700; G.W.) National Natural Science Foundation of China grants 81173114, 81072688, and 81473282 (G.W.). This work was partially done at Vanderbilt with support from NIH grant OD12387 (G.W.).

Disclosures: None declared.

Current address of G.W., Center of Translational Cancer Research and Therapy, State Key Laboratory of Molecular Oncology, Cancer Hospital and Institute, Chinese Academy of Medical Sciences and Peking Union Medical College, Beijing, China; of S.H., First Affiliated Hospital, Sun Yat-sen University, Guangzhou, China. 
Outside of renal transplantation, few effective treatments of ADPKD currently exist. To eventually use causal gene replacement in treating human ADPKD patients, we applied the human PKD2 transgene in orthologous ADPKD mouse models that were previously generated by us. ${ }^{21}$ We therefore developed a transgenic mouse model that expresses human $P K D 2$ under the pCAGGS ubiquitous transgenic promoter $\left(P K D 2^{\mathrm{tg}}\right) . P K D 2^{\mathrm{tg}}$ tissues, such as the kidney and liver, showed overexpression of the human $P K D 2$ gene product polycystin (PC)-2. There was no significant cystic phenotype resulting from $\mathrm{PC} 2$ overexpression in the kidney, liver, or pancreas. We produced a compound $P k d 2^{-l-} ; P K D 2^{\mathrm{tg}}$ mouse line by cross-mating the $P K D 2^{\text {tg }}$ mice with $P k d 2^{-1-}$ mice. ${ }^{21} P k d 2^{-/-}$mice with a $P K D 2^{\text {tg }}$ allele escaped embryonic lethality and survived up to 12 months, although moderate to severe cystic phenotypes still developed in the kidney, liver, and pancreas. Notably, the renal and hepatic cystic severity was significantly ameliorated in $P k d 2^{-/-}$mice with homozygous $P K D 2^{\mathrm{tg}}$ alleles $\left(P k d 2^{-1-} ; P K D 2^{\mathrm{tg} / \mathrm{tg}}\right)$ compared to that in the $P k d 2^{-1-}$ mice with a hemizygous $P K D 2^{\text {tg }}$ allele $\left(P k d 2^{-1-} ; P K D 2^{\mathrm{tg}}\right)$. Our findings indicated that the functional expression of human PC2 not only did not induce hepatorenal cystogenesis but also significantly rescued ADPKD phenotypes in a dose-dependent manner. These findings provided a basis for considering functional gene replacement in the treatment of ADPKD.

\section{Materials and Methods}

\section{Generation of Transgenic Mice with Human PKD2}

To construct human PKD2 transgenic mice, the full-length human $P K D 2$ open reading frame cDNA was cloned into the XhoI and KpnI type 2 restriction enzyme sites of the pCAGGS expression vector. ${ }^{22}$ The human PKD2 transgene construct was then released from the rest of the vector by digestion with SalI and AvrII restriction enzymes (Supplemental Figure $\mathrm{S} 1 \mathrm{~A})$. The PKD2 transgene construct was microinjected into the pronuclei of fertilized C57BL/6J oocytes, which were then transferred into the oviducts of pseudopregnant mice. Founder mice were screened for the transgene by PCR analysis of genomic DNA extracted from the tail (Supplemental Figure S1B). The forward and reverse primers for PCR screening were targeted against part of the construct from the vector backbone and human PKD2 cDNA, respectively (forward, 5'-TGCTAACCATGTTCATGCCTTC- $3^{\prime}$; reverse, $5^{\prime}$-CTGGAGTTCACCATCGCG-3'). The $P K D 2$ transgene was confirmed and its copy number was determined by Southern blot analysis (Supplemental Figure S1C). For Southern blots, genomic DNA was digested with the NotI enzyme, resolved on an agarose gel, transferred to a nylon membrane, and hybridized to a ${ }^{32} \mathrm{P}$ labeled probe, which was the PCR product amplified by primers against the pCAGGS promoter region (forward, $5^{\prime}$ CGGGGTCATTAGTTCATAGC-3'; reverse, 5'-GAGTGAAGCAGAACGTGGG-3').
The gene-targeted mouse models of $P k d 2$ were previously described. ${ }^{21,23}$ Nestin-Cre transgenic mice were purchased from Jackson Laboratories (stock no. 003771; Bar Harbor, ME). All of the mouse models used in this study were on the C57BL/6J inbred background.

\section{RT-PCR and Quantitative PCR}

The total RNA was isolated from the tissues of transgenic and wild-type mice using Trizol (Life Technologies, Grand Island, NY). The cDNA was then generated from the total RNA $(2 \mu \mathrm{g})$ using SuperScript II Reverse Transcriptase according to the manufacturer's protocol (Life Technologies). The primer pairs used for analysis were: human PKD2: forward, 5'-TCCATCGGCAGCATAGTGT- $3^{\prime}$ and reverse, 5'-GGCGAGGTTGACCATTTAG-3'; mouse $P k d 2$ : forward, 5'-CTCTTTACCACGTCCGATGA-3' and reverse, 5'-GGAAACGATGCTGCCAAT- $3^{\prime}$; and human GAPDH as a mRNA loading control: forward, 5'-GACCACAGTCCATGCCATCAC-3' and reverse, $5^{\prime}$-TCCACCACCCTGTTGCTGTA- $3^{\prime}$. The PCR products were separated by $1.5 \%$ agarose gel electrophoresis. Quantitative PCR was performed using the iCycler iQ RealTime PCR Detection System with the iQ SYBR Green Supermix kit (Bio-Rad Laboratories, Hercules, CA). The primers were the same as those used for the RT-PCR.

\section{Western Blot Analysis}

Tissues isolated from sacrificed mice were homogenized in lysis buffer. The protein concentration was determined by bicinchoninic acid assay (Life Technologies). Samples were separated by SDS-PAGE and then electrotransferred to a nylon membrane (PerkinElmer, Waltham, MA). The membrane was incubated with primary antibodies at room temperature for 4 hours and then with peroxidase-conjugate secondary antibodies for 1 hour and detected with enhanced chemiluminescence (Life Technologies). The Western blot results were quantified using the densitometry values of the immunoreactive bands for targeted proteins normalized to the total $\beta$-actin (loading control).

\section{Antibodies and Reagents}

The following antibodies, staining materials, and reagents were used: anti-PC2 polyclonal antisera (hPKD2-Cp and C2), generated in our previous study ${ }^{16,24}$; anti- $\beta$-actin antibody and DAPI (Sigma-Aldrich, St. Louis, MO); anti-Tamm-Horsfall glycoprotein antibody (Applied Biological Materials, Aldinga Beach, SA, Australia); fluorescein Lotus tetragonolobus lectin and fluorescein Dolichos biflorus agglutinin (Vector Laboratories, Burlingame, CA); anti-aquaporin-2, anti-proliferating cell nuclear antigen (PCNA), and anti-Ki67 antibodies (Abcam, Cambridge, MA); and anti-phosphorylated Akt (Ser473), anti-total Akt, anti-phosphorylated c-Raf (Ser338), anti-total c-Raf, anti-phosphorylated MEK1/2 (Ser217/221), anti-total 

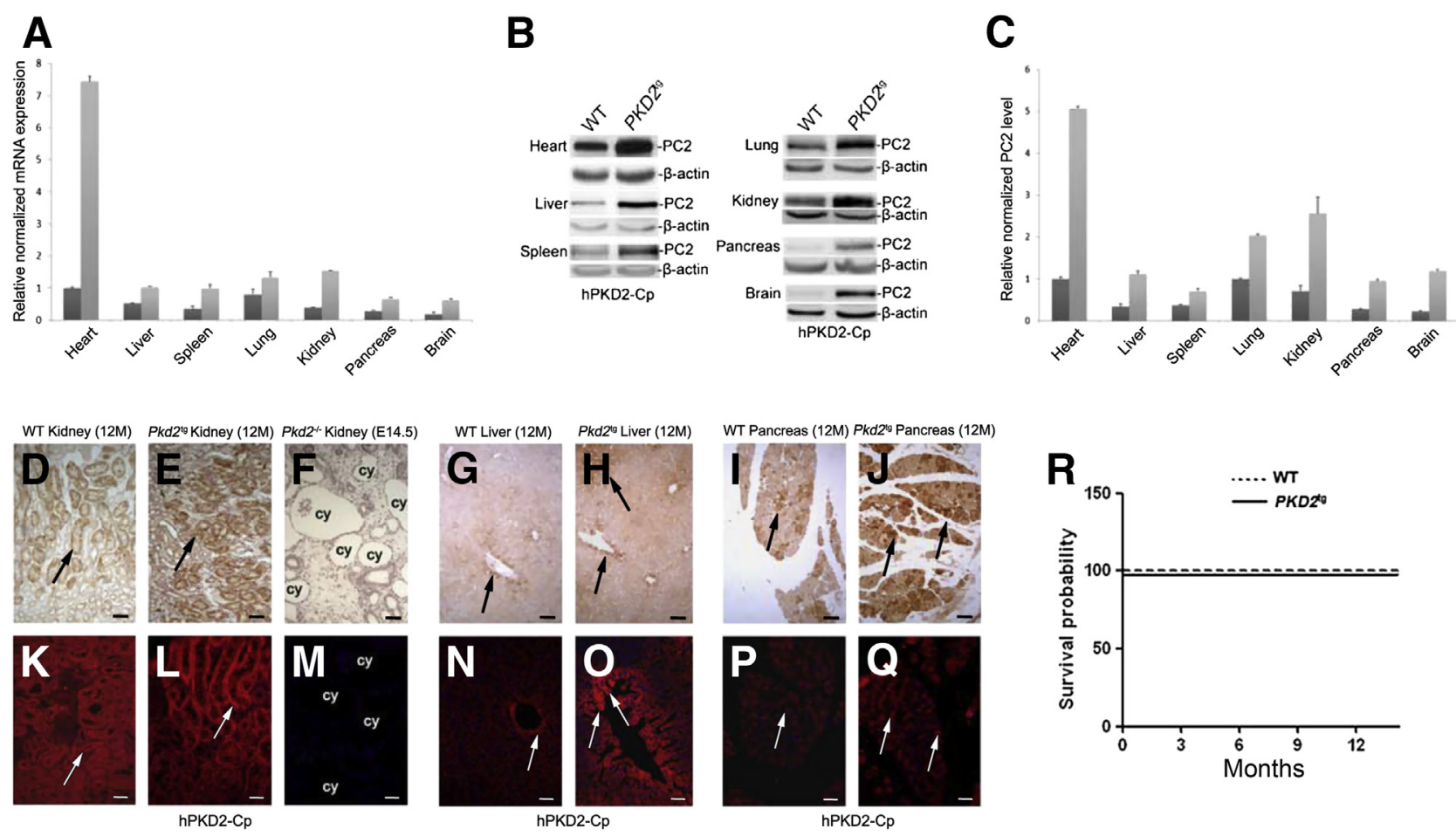

Figure 1 Characterization of the human PKD2 transgenic mouse line $\left(P K D 2^{\mathrm{tg}}\right)$. A: Human $P K D 2 \mathrm{mRNA}$ expression versus endogenous $P k d 2 \mathrm{mRNA}$ expression in different organs/tissues of $P K D 2^{\text {tg }}$ (light gray bars) mice and their wild-type (WT; dark gray bars) littermates, determined by quantitative PCR. All quantitative PCR results were normalized to the glyceraldehyde-3-phosphate dehydrogenase (GAPDH) expression. B: Proteins extracted from the same organs/tissues of $P K D 2^{\text {tg }}$ mice and their wild-type littermates were analyzed by Western blot with an anti- polycystin (PC)-2 antibody (hPKD2-Cp). Markedly higher PC2 expression is detected in the organs/tissues of $P K D 2^{\text {tg }}$ mice than in those of their wild-type littermates. $\beta$-Actin was used as an internal loading control. C: Quantitative analysis of the densitometry values of the Western blot analyses. At least three transgenic mice or their wild-type littermates were tested. D-Q: IHC analysis (IHC) (D-J) and immunofluorescence (IF) (K-Q) staining with the hPKD2-Cp antibody to detect PC2 in the kidneys of 12 -month-old $P K D 2^{\text {tg }}$ transgenic mice and their wild-type littermates. A Pkd2-null embryonic kidney (embryonic day 14.5, E14.5) was used as a negative control. Obvious positive labeling (arrows) is seen in both the $P K D 2^{\mathrm{tg}}$ and wild-type-littermate kidneys, but it is much stronger in the $P K D 2^{\text {tg }}$ kidney (arrows in $\mathbf{D}$ versus $\mathbf{E}$ and in $\mathbf{K}$ versus $\mathbf{L}$ ). There is no positive signal in the $P k d 2$-null embryonic kidney $(\mathbf{F}$ and $\mathbf{M})$. IHC ( $\mathbf{G}$ and $\mathbf{H})$ and IF (N and $\mathbf{0})$ staining analyses were used for examine the liver of these mice. Stronger positive staining (arrows in $\mathbf{G}$ versus $\mathbf{H}$ and $\mathbf{N}$ versus $\mathbf{0}$ ) is detected in the $P K D 2^{\text {tg }}$ liver than in the wild-type-littermate liver. Similar IHC and IF staining results were obtained in the pancreas of these mice (arrows in I versus $\mathbf{J}$ and in $\mathbf{P}$ versus $\mathbf{Q}$ ). $\mathbf{R}$ : Kaplan-Meier survival analysis of wild-type and $P K D 2^{\mathrm{tg}}$ mice. No difference in survival rate is seen between the wild-type and $P K D 2^{\text {tg }}$ mice up to 12 months of age ( $n=25$ per genotype). Data presented as means \pm SD (A and $\left.\mathbf{C}\right)$. Scale bars: $50 \mu \mathrm{m}(\mathbf{D}-\mathbf{J}) ; 100 \mu \mathrm{m}(\mathbf{K}-\mathbf{Q})$. cy, cyst; M, months.

MEK1/2, anti-phosphorylated p44/42 MAPK (Erk1/2) (Thr202/Try204), anti-total p44/42 MAPK (Erk1/2) anticleaved caspase-3 (Asp 175), anti-caspase-3 antibody (Cell Signaling Technology, Danvers, MA). Secondary antibodies included cyanine 2-conjugated donkey anti-sheep IgG and cyanine 3-conjugated goat anti-rabbit IgG (Jackson ImmunoResearch Laboratories, West Grove, PA) and peroxidaseconjugated rabbit anti-mouse IgG and peroxidase-conjugated goat anti-rabbit IgG (Promega, Madison, WI).

\section{Histological Examination, Immunofluorescence, and Immunohistochemical Analysis}

The detailed procedures used for histological examination, immunofluorescence, and immunohistochemical analysis staining were published previously. ${ }^{23,25}$ For microscopic analyses, an Axioplan 2IE research microscope and an Axiovert 200 inverted microscope system (Carl Zeiss, Oberkochen, Germany), with $10 \times, 20 \times$, and $40 \times$ objectives, were used. The Aperio ScanScope system (Leica
Microsystems, Buffalo Grove, IL) was also used for histological analyses, and digital graphics were viewed and analyzed using ImageScope viewer software version 12.1.0.5029 (Leica).

\section{Proliferation and Apoptosis}

To examine cell proliferation, kidney samples were fixed in $4 \%$ buffered paraformaldehyde (Sigma-Aldrich), embedded in paraffin, and cut into sections on a microtome. After deparaffinization and rehydration, the samples on slides were washed in $1 \times$ phosphate-buffered saline three times for 5 minutes each. Microwave retrieval with citrate buffer (pH 6.0) was used for epitope unmasking. The slides were then immersed in 3\% hydrogen peroxide for 10 minutes to inactivate endogenous peroxidase, washed with $1 \times$ phosphate-buffered saline three times for 5 minutes each, and blocked with $2 \%$ bovine serum albumin for 1 hour. The slides were then incubated with an anti-Ki67 or anti-PCNA antibody overnight at $4^{\circ} \mathrm{C}$. After incubation with a cyanine 

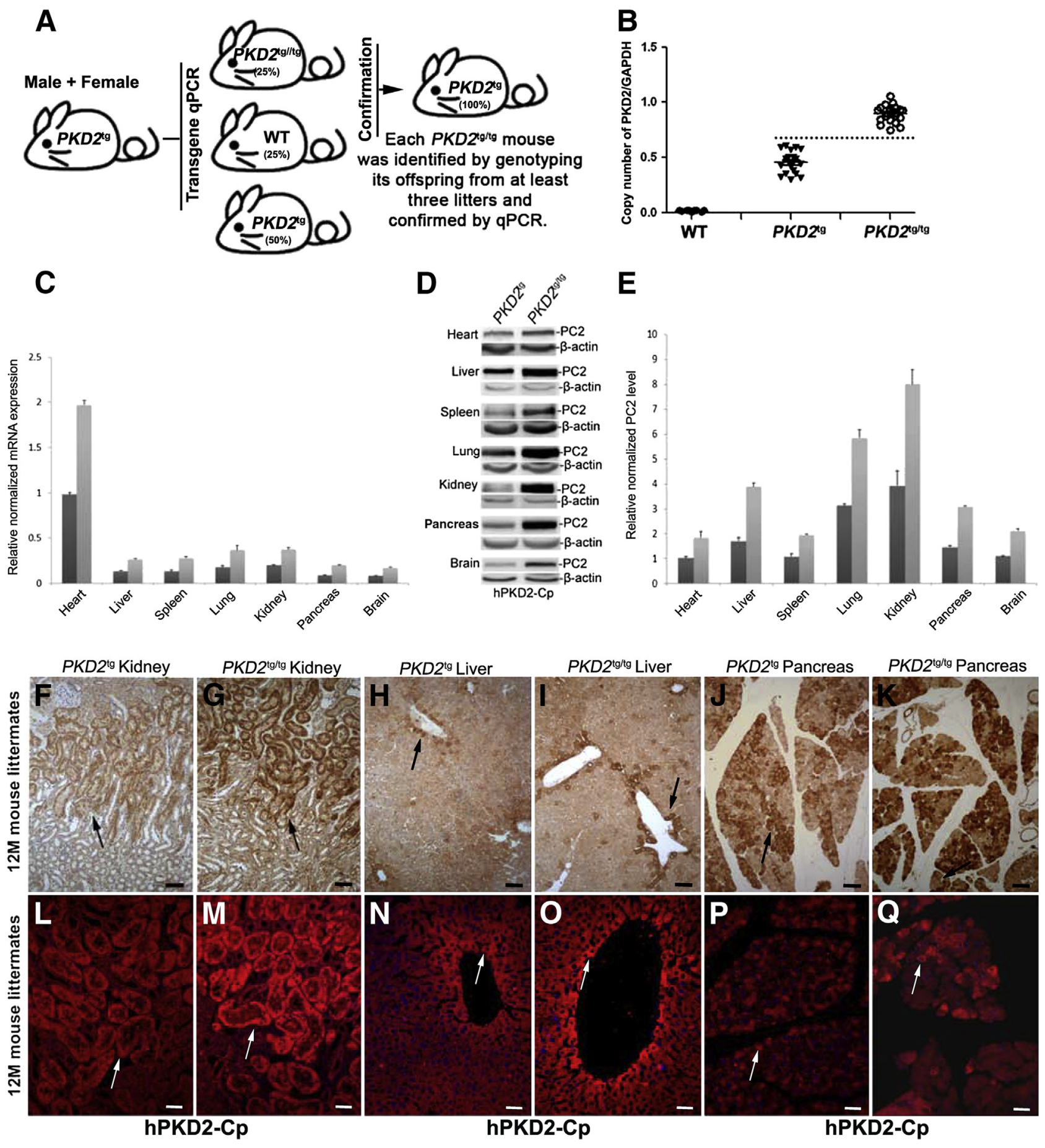

Kidney

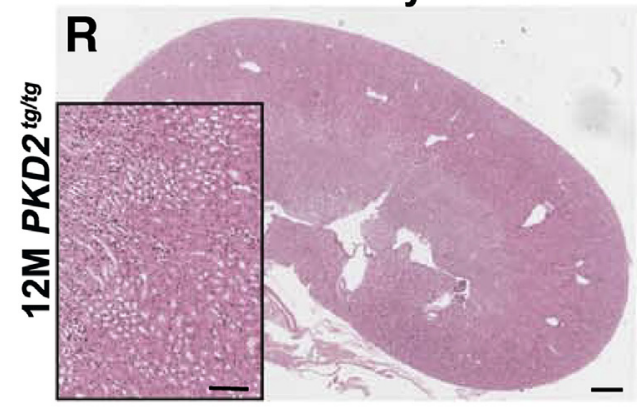

Liver

Pancreas

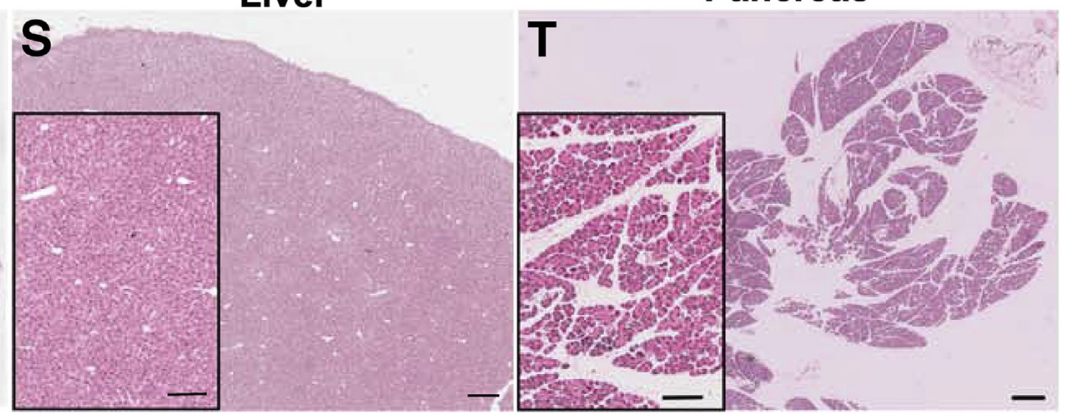


3-conjugated goat anti-rabbit secondary antibody, the slides were stained with DAPI to identify all of the cell nuclei. Proliferation was measured by counting of the Ki67-positive or PCNA-positive nuclei. Nuclei were counted in three randomly chosen high-power fields $(20 \times)$ for each sample.

Apoptosis was detected using the DeadEnd Fluorometric terminal deoxynucleotidyl transferase dUTP nick end labeling (TUNEL) kit (Promega) according to the manufacturer's manual or by immunofluorescence staining for cleaved Casp3. For the TUNEL assay, after deparaffinization and rehydration, the slides of kidney samples were fixed in $4 \%$ formaldehyde in $1 \times$ phosphate-buffered saline for 15 minutes and then permeabilized by proteinase $\mathrm{K}$ for 10 minutes. After being washed in phosphate-buffered saline, the samples were equilibrated and labeled for 60 minutes. The samples were then immersed in $2 \times$ saline sodium citrate to stop the reaction, and counterstained with DAPI. Positive apoptosis signals were detected by fluorescence microscopy. The method of cleaved Casp3 staining was similar to PCNA and Ki67 staining. Apoptotic cells were counted in the same manner as were the proliferation markers.

\section{Statistical Analysis}

All assays were repeated at least three times in duplicate or triplicate, and graphic data are presented as means \pm SD unless otherwise stated. Statistical analysis was performed where appropriate using the Student's $t$-test or one-way analysis of variance, followed by the Tukey multiple-comparison test. $P<0.05$ was considered statistically significant.

\section{Results}

\section{Development of a Human PKD2 Transgenic Mouse Model Lacking Renal Cystic Phenotypes}

To investigate the in vivo function of human PC2 in mice, we generated a transgenic mouse $\left(P K D 2^{\mathrm{tg}}\right)$ that carries the full-length human $P K D 2$ open reading frame cDNA under control of the cytomegalovirus immediate early enhancer and the chicken $\beta$-actin promoter (Supplemental Figure S1, $\mathrm{A}$ and B). Southern blot analysis revealed that this $P K D 2^{\mathrm{tg}}$ mouse carried four copies of the transgene (Supplemental Figure S1C).

To characterize the $P K D 2^{\text {tg }}$ mouse line, we performed quantitative PCR using primers specific for the human $P K D 2$ cDNA or for the wild-type mouse $P k d 2$ cDNA. The human $P K D 2$ mRNA was much more greatly expressed than the mouse $P k d 2$ mRNA in all of the tissues and organs tested, including the heart, liver, spleen, lung, kidney, pancreas, and brain (Figure 1A). Relatively high human $P K D 2$ expression was seen in the heart and kidneys. Compared to the endogenous $P k d 2$ mRNA levels, the human $P K D 2$ expression was approximately sevenfold in the $P K D 2^{\mathrm{tg}}$ heart, fourfold in the kidney, and twofold in the liver and pancreas. Western blot analysis of PC2 in the tested tissues showed protein expression levels similar to the quantitative PCR results (Figure 1, B and C). Immunohistochemistry analysis and immunofluorescence staining also showed that compared to that in the wild-type littermates, markedly stronger PC2 expression was detected in the kidney, liver, and pancreas of the $P K D 2^{\text {tg }}$ mice (Figure $1, \mathrm{D}-\mathrm{Q}$ ).

The $P K D 2^{\mathrm{tg}}$ mice did not show any gross or microscopic cystic phenotypes in the kidney (Figure 1E), liver (Figure 1H), or pancreas (Figure $1 \mathrm{~J}$ ). In addition, over the 12-month observation period, none of the $P K D 2^{\text {tg }}$ mice died, and their survival rate was not significantly different from that of their wild-type littermates (Figure 1R). These findings indicate that $P K D 2^{\mathrm{tg}}$ mice ectopically expressed the human orthologue of PC2 and showed neither abnormal mortality nor cystic phenotypes.

To determine whether a different number of transgenes could affect the expression level of PC2 in vivo and/or induce abnormal phenotypes, as previously reported, ${ }^{26,27}$ we mated male and female hemizygous $P K D 2$-transgenic mice $\left(P K D 2^{\mathrm{tg}}\right)$ to produce homozygous $P K D 2$-transgenic mice $\left(P K D 2^{\mathrm{tg} / \mathrm{tg}}\right)$. The homozygous transgenic mice, $P K D 2^{\text {tg/tg }}$, were identified by determining whether mating the candidate $P K D 2^{\mathrm{tg} / \mathrm{tg}}$ mouse with a wild-type mouse generated offspring that were all positive for the hemizygous transgene in at least three litters (Figure 2A), and whether quantitative PCR analysis of human PKD2 expression in the genomic DNA from the transgenic mice showed a fold-difference from that of the hemizygous parents (Figure 2B). Once the candidate $P K D 2^{\text {tg/tg }}$ mice were confirmed by both approaches, male and female $P K D 2^{\mathrm{tg} / \mathrm{tg}}$

\footnotetext{
Figure 2 Generation and characterization of homozygous human PKD2 transgenic mice $\left(P K D 2^{\mathrm{tg} / \mathrm{tg}}\right)$. A: Mating strategy. Male and female hemizygous $P K D 2$ transgenic mice $\left(P K D 2^{\mathrm{tg}}\right)$ were mated to generate $P K D 2^{\mathrm{tg} / \mathrm{tg}}$ mice. $P K D 2^{\mathrm{tg} / \mathrm{tg}}$ mice were determined by genotyping the offspring from mating pairs of candidate $P K D 2^{\mathrm{tg} / \mathrm{tg}}$ and wild-type (WT) mice; all of the offspring were expected to have been $P K D 2^{\mathrm{tg}}$ positive. B: The candidate $P K D 2^{\mathrm{tg} / \mathrm{tg}}$ mice were then confirmed by performing quantitative PCR of the tail genomic DNA with human transgene primers and comparing the results to age-matched wild-type and $P K D 2^{\text {tg }}$ mice. The ratio of the copy number of $P K D 2$ to glyceraldehyde-3-phosphate dehydrogenase (GAPDH) is over 0.75 in $P K D 2^{\text {tg/tg }}$ mice, but below 0.6 in $P K D 2^{\text {tg }}$ mice. Wildtype mice were used as a negative control. C: Human PKD2 mRNA expression in different organs/tissues of $P K D 2^{\text {tg }}$ (dark gray bars) and $P K D 2^{\text {tg/tg }}$ (light gray bars) mice, determined by quantitative PCR analysis. The $P K D 2 \mathrm{mRNA}$ expression level of $P K D 2^{\mathrm{tg} / \mathrm{tg}}$ mice is almost as twice that of the $P K D 2^{\mathrm{tg}}$ mice $(n=3$ per genotype). D: Polycystin (PC)-2 levels in different organs/tissues of $P K D 2^{\mathrm{tg}}$ and $P K D 2^{\mathrm{tg} / \mathrm{tg}}$ mice, determined by Western blot analyses with the anti-PC2 antibody (hPKD2-Cp). $\beta$-Actin was used as an internal loading control. E: Quantitative analysis of the Western blot results. $\mathbf{F}-\mathbf{Q}$ : IHC analysis (F-K) and immunofluorescence ( $\mathbf{L}-\mathbf{Q})$ staining with the hPKD2-Cp antibody in the kidney, liver, and pancreas shows much higher PC2 labeling in 12-month-old (12M) $P K D 2^{\text {tg/tg }}$ mice than in age-matched $P K D 2^{\text {tg }}$ mice (arrows) $(\mathbf{F}, \mathbf{L}$ versus $\mathbf{G}, \mathbf{M}, \mathbf{H}, \mathbf{N}$ versus $\mathbf{I}, \mathbf{0}$ and $\mathbf{J}$, $\mathbf{P}$ versus $\mathbf{K}, \mathbf{Q})$. $\mathbf{R}-\mathbf{T}$ : Histological analysis reveals no obvious cysts in these samples. $n=9(\mathbf{B}, \mathrm{WT}) ; n=18\left(\mathbf{B}, P K D 2^{\mathrm{tg}}\right) ; n=20\left(\mathbf{B}, P K D 2^{\mathrm{tg} / \mathrm{tg}}\right)$. Data expressed as means \pm SD $(\mathbf{C}$ and $\mathbf{E})$. Scale bars: $50 \mu \mathrm{m}(\mathbf{F}-\mathbf{K})$; $100 \mu \mathrm{m}(\mathbf{L}-\mathbf{Q}$ and boxed areas of $\mathbf{R}-\mathbf{T}) ; 500 \mu \mathrm{m}(\mathbf{R}-\mathbf{T})$. M, month; qPCR, quantitative PCR.
} 
A

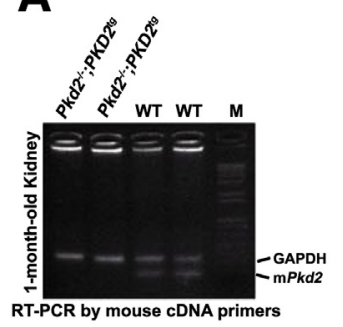

B

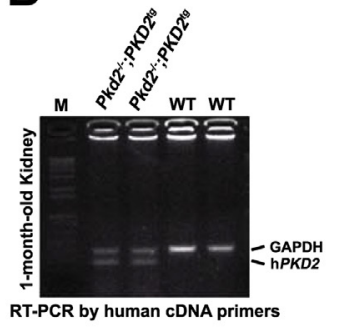

C

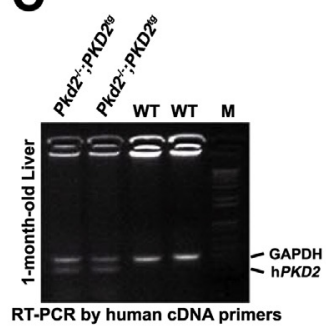

D

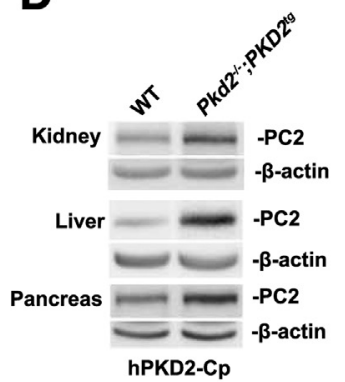

E

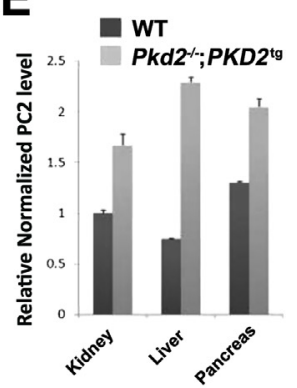

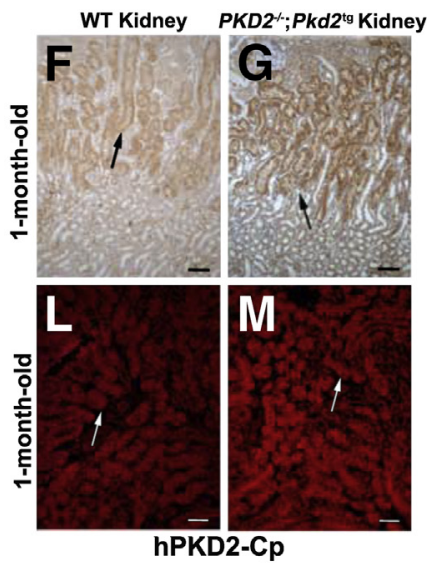
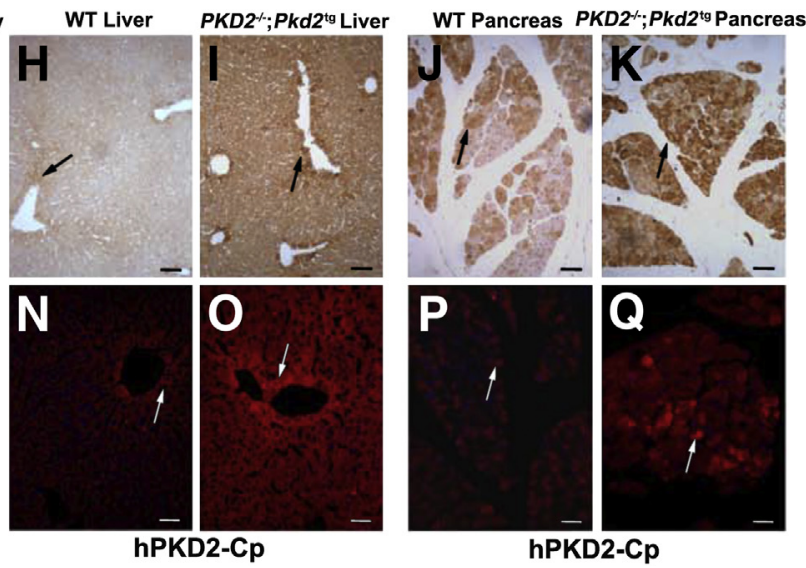

R

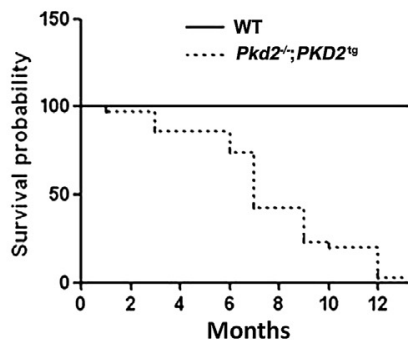

Figure 3 Identification and characterization of compound $P k d 2$-null mice with a human $P K D 2$ transgene $\left(P k d 2^{-/-} ; P K D 2^{\mathrm{tg}}\right)$. A: $\mathrm{cDNAs}$ transcribed from the total RNA of 1-month-old $P k d 2^{-/-} ; P K D 2^{\text {tg }}$ and age-matched wild-type (WT) kidneys were used for RT-PCR with a pair of mouse $P k d 2$ cDNA primers. A positive band is observed in wild-type, but not in $P k d 2^{-1-} ; P K D 2^{\mathrm{tg}}$, mice. B: Similar RT-PCR analyses were performed with a pair of human $P K D 2$ cDNA primers. A positive band is seen in the $P k d 2^{-I-} ; P K D 2^{\text {tg }}$, but not the wild-type, kidneys. C: The same RT-PCR results are obtained in liver. Glyceraldehyde-3-phosphate dehydrogenase (GAPDH) mRNA was used as a loading control. D: Western blot analyses of organs/tissues of 1-month-old wild-type and $P k d 2^{-/-} ; P K D 2^{\text {tg }}$ mice using the anti-polycystin (PC)-2 antibody (hPKD2-Cp). PC2 is detected in the kidney, liver, and pancreas of Pkd2-null mice with human PKD2 transgene. $\beta$-Actin was used as a loading control. E: Quantitative analyses of the Western blot results show that PC2 expression is significantly higher than in the wild-type organs. IHC analysis (IHC) (F and $\mathbf{G}$ ) and immunofluorescence (IF) ( $\mathbf{L}$ and $\mathbf{M}$ ) staining with the hPKD2-Cp antibody to detect PC2 in the kidneys of 1-month-old wildtype and $P k d 2^{-/-} ; P K D 2^{\text {tg }}$ mice. Stronger positive staining (arrows in $\mathbf{F}$, $\mathbf{L}$ versus $\mathbf{G}, \mathbf{M}$ ) is seen in the $P k d 2^{-1-} ; P K D 2^{\text {tg }}$ kidney than in the age-matched wild-type kidney. IHC $(\mathbf{H}-\mathbf{K})$ and IF ( $\mathbf{N}-\mathbf{Q})$ staining analyses were used for examine the liver and pancreas of these mice. All results are similar to the kidneys' staining (arrows in $\mathbf{H}, \mathbf{N}$ versus $\mathbf{I}, \mathbf{0}$ and $\mathbf{J}, \mathbf{P}$ versus $\mathbf{K}, \mathbf{Q}$ ). R: Kaplan-Meier survival analysis of wild-type and $P k d 2^{-1-} ; P K D 2^{\text {tg }}$ mice. The median survival rate of the $P k d 2^{-/-} ; P K D 2^{\text {tg }}$ mice was around 6 months. $n=25$ (R, per genotype). Data expressed as means \pm SD (E). Scale bars: $50 \mu \mathrm{m}(\mathbf{F}-\mathbf{K}) ; 100 \mu \mathrm{m}(\mathbf{L}-\mathbf{Q})$. M, marker.

mice were intercrossed to generate enough $P K D 2^{\text {tg/tg }}$ mice for further analysis. The expressions of $P K D 2$ and its gene product PC2 in different tissues were significantly greater in the homozygous $P K D 2^{\mathrm{tg} / \mathrm{tg}}$ mice than in the hemizygous $P K D 2^{\mathrm{tg}}$ mice, as shown by quantitative PCR and Western blot analyses (Figure 2, C and D). As expected, the PC2 level in the homozygous transgenic mice was nearly twice that seen in the hemizygous transgenic mice (Figure 2E). Immunohistochemical analysis and immunofluorescence staining with the anti-PC2 antibody also showed markedly greater $\mathrm{PC} 2$ expression in the $P K D 2^{\text {tg }}{ }^{\mathrm{tg}}$ kidney than in the $P K D 2^{\mathrm{tg}}$ kidney (Figure $2, \mathrm{~F}$ and $\mathrm{L}$ versus $\mathrm{G}$ and $\mathrm{M}$, respectively). The liver (Figure 2, $\mathrm{H}$ and $\mathrm{N}$ versus I and $\mathrm{O}$, respectively) and pancreas (Figure 2, $\mathrm{J}$ and $\mathrm{P}$ versus $\mathrm{K}$ and $\mathrm{Q}$, respectively) showed similar findings. These results indicate that the transgene expression level in vivo could be determined by the copy number of the transgenes.

We next examined whether the greater PC2 expression induced abnormal developmental defects and cystic phenotypes in the $P K D 2^{\mathrm{tg} / \mathrm{tg}}$ mice. Over 12 months, none of the $P K D 2^{\mathrm{tg} / \mathrm{tg}}$ mice died, and there was no significant difference in survival between the wild-type and the $P K D 2^{\mathrm{tg} / \mathrm{tg}}$ mice $(n=25$ per group; data not shown). There were also no obvious gross or microscopic cystic phenotypes in the kidney (Figure $2 \mathrm{R}$ ), liver (Figure 2S), or pancreas (Figure 2T) in the 12-month-old $P K D 2^{\mathrm{tg} / \mathrm{g}}$ mice. We also examined renal function in the $P K D 2^{\mathrm{tg}}$ and $P K D 2^{\mathrm{tg} / \mathrm{tg}}$ mice. Compared to those in the age-matched wild-type mice, there was no statistically significant difference in the serum blood urea nitrogen (BUN) and creatinine (CRE) levels in the $P K D 2^{\mathrm{tg}}$ or $P K D 2^{\mathrm{tg} / \mathrm{tg}}$ mice at any age tested (Supplemental Figure S2). These results indicate that we developed a transgenic mouse model that greatly expressed human PC2 without overt cystic or functional phenotypes.

\section{Ectopically Expressed Human PC2 Fully Rescues Embryonic Lethality in Pkd2-Null Mice}

The loss of PC2 in mice causes embryonic lethality between embryonic days (E) 13.5 and 15.5, and the embryos show obvious renal and pancreatic cysts. ${ }^{21}$ To determine whether 


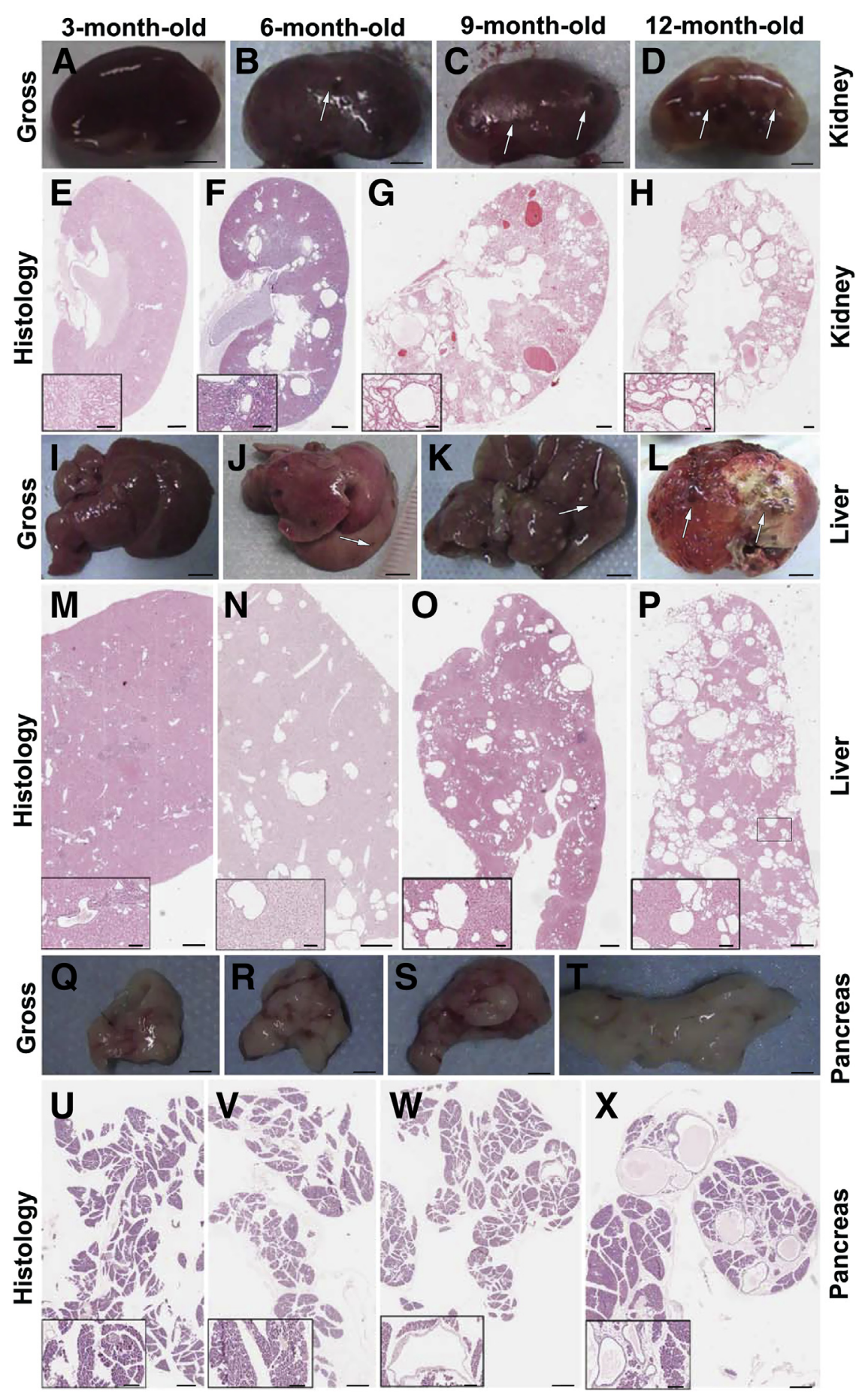

Figure 4 Cystic phenotypes in the $P k d 2^{-/} ; P K D 2^{\mathrm{tg}}$ mice. There are no gross cysts in the 3-month-old $P k d 2^{-/-} ; P K D 2^{\text {tg }}$ kidney (A). Gross cysts are seen in the 6- and 9-month-old kidneys (arrows) (B and $\mathbf{C}$ ), and massive gross cysts occur in the 12-month-old kidneys (D). Histological analyses of the same kidneys show findings similar to those from the gross examinations $(\mathbf{E}-\mathbf{H})$. Gross cysts also occur in the 6-month-old $P k d 2^{-1-} ; P K D 2^{\text {tg }}$ liver (arrow), and the 9- and 12-month-old livers show severe cystic phenotypes that worsened with age $(\mathbf{I}-\mathbf{L})$. Histological examinations of the same livers (M-P). No gross cysts are found in the $P k d 2^{-/-} ; P K D 2^{\mathrm{tg}}$ pancreas up to the age of 12 months (Q-T). Although there are no histological cysts in the 3- and 6-month-old pancreas ( $\mathbf{U}$ and $\mathbf{V})$, a few cystic lesions are seen in the sections of the 9- and 12-monthold pancreas ( $\mathbf{W}$ and $\mathbf{X}$ ) stained with hematoxylin and eosin. Scale bars: $2 \mathrm{~mm}(\mathbf{A}-\mathbf{D}) ; 4$ $\mathrm{mm}(\mathbf{I}-\mathbf{L}) ; 1 \mathrm{~mm}(\mathbf{Q}-\mathbf{T}) ; 500 \mu \mathrm{m}(\mathbf{E}-\mathbf{H}, \mathbf{M}-\mathbf{P}$, $\mathbf{U}-\mathbf{X}$ ); $100 \mu \mathrm{m}$ (insets).

the human $P K D 2$ transgene could rescue the embryonically lethal phenotype associated with PC2 loss, we crossed the $P K D 2$ transgenic mice $\left(P K D 2^{\mathrm{tg}}\right)$ with $P k d 2$ heterozygous mice $\left(P k d 2^{+--}\right)$to produce compound $P k d 2^{-/-} ; P K D 2^{\text {tg }}$ mice. Although no endogenous $P k d 2$ was seen in the kidneys of $P k d 2^{-1-} ; P K D 2^{\text {tg }}$ mice by RT-PCR using a pair of mouse $P k d 2$ cDNA primers (Figure $3 \mathrm{~A}$ ), human $P K D 2$ mRNA by using human $P K D 2$ cDNA primers was detected in the kidneys and liver of these mice (Figure 3, B and C). To determine whether ectopically expressed human PC2 can be appropriately restored in the organ and tissue of $P k d 2$ null mice, we performed Western blot analyses to evaluate expressional levels of PC2 in $P k d 2^{-/-}$mice with $P K D 2$ transgene $\left(P k d 2^{-/-} ; P K D 2^{\mathrm{tg}}\right)$. The Western blot results showed that the expressed PC2 could be detected in the kidneys, liver, and pancreas of $P k d 2^{-/-} ; P K D 2^{\mathrm{tg}}$ mice, even significantly more than that in age-matched wild types (Figure 3, D and E). By immunohistochemical analysis and immunofluorescence staining with the same antibody, positive PC2 labeling in the kidney (Figure 3, F and L versus G 

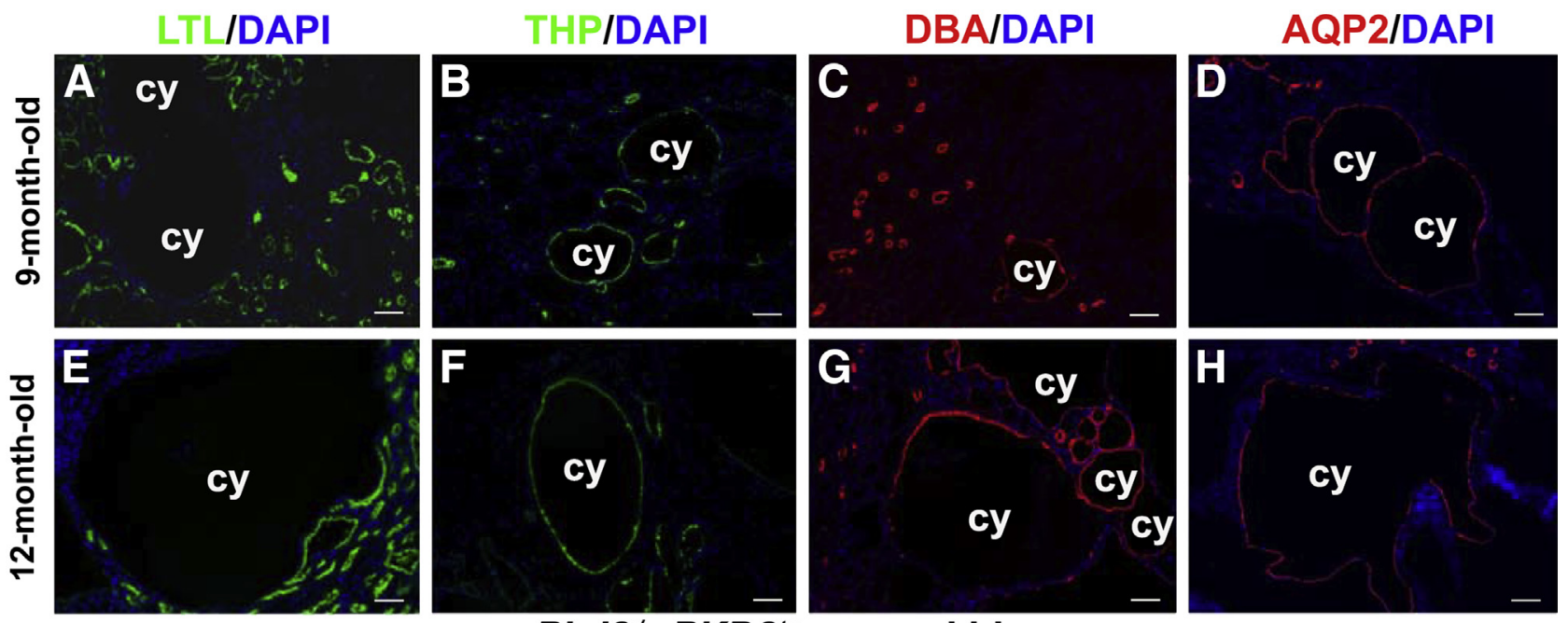

\section{Pkd2 $^{-/} ;$PKD2 $^{\text {tg }}$ mouse kidneys}

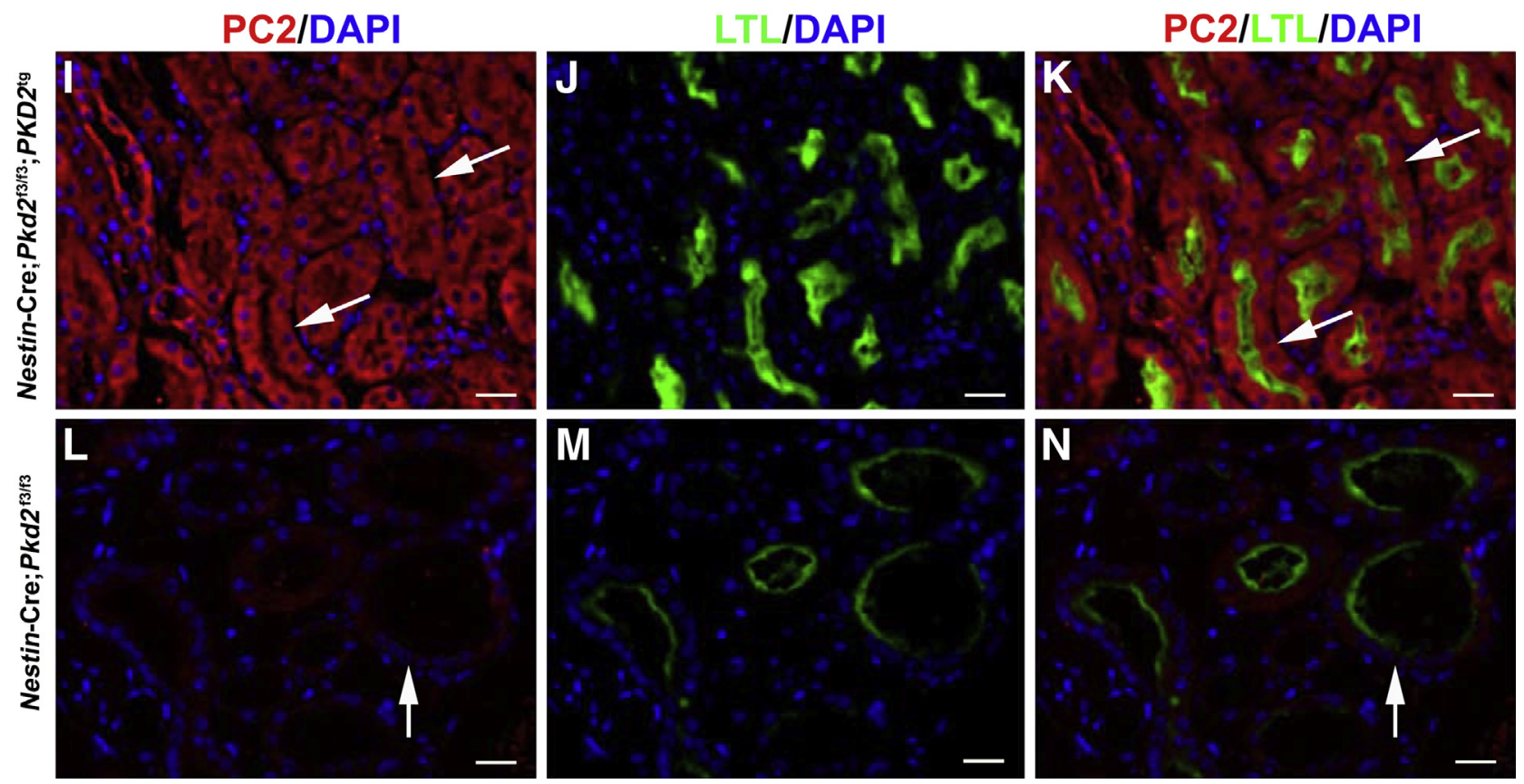

Figure 5 Segmental origin of tubular cysts in the $P k d 2^{-/-} ; P K D 2^{\text {tg }}$ kidneys. A-H: The origins of cystic tubules in the $P k d 2^{-/-} ; P K D 2^{\mathrm{tg}}$ kidneys were determined using immunofluorescence of nephronic markers: Lotus tetragonolobus lectin (LTL) for the proximal tubules; Tamm-Horsfall glycoprotein (THP) for the distal tubules; Dolichos biflorus agglutinin (DBA); and anti-aquaporin (AQP)-2 for the collecting ducts. A: Positive LTL labeling is detected in some dilated proximal tubules of the 9-month-old $P k d 2^{-/-} ; P K D 2^{\text {tg }}$ kidney. B: Surrounding cystic staining that originated from the distal tubules is detected by THP staining in the same kidney. C and D: Cysts that were positive for DBA and AQP2 were also observed in the kidney. E-H: Similar findings were made in the 12-month-old $P k d 2^{-1-} ; P K D 2^{\mathrm{tg}}$ kidney. I-N: Polycystin (PC)-2 re-expression in the kidneys of 1 -month-old Nestin-Cre;Pkd2 $2^{\mathrm{f} 3 / \mathrm{f3}} ; P K D 2^{\mathrm{tg}}$ and Nestin-Cre;Pkd2 $2^{\mathrm{f} 3 / \mathrm{f3}}$ mice. The kidneys were co-stained by an anti-PC2 polyclonal antibody (I) and LTL (J). The merged image (K) shows that LTL-positive tubules (green) have overt PC2 expression (red) in the kidney of Nestin-Cre; $P k d 2^{\mathrm{f} 3 / \mathrm{f3}} ; P K D 2^{\mathrm{tg}}$ mice (arrows). By the same staining $(\mathbf{L}-\mathbf{N}), P C 2$ expression (red) significantly decreases in dilated LTL-positive tubules (green) of the Nestin-Cre;Pkd2 $2^{\mathrm{f} 3 / \mathrm{f3}}$ kidney (arrow). DAPI dye (blue) was used for stain nuclei. $n=5$ (E-H, 9- or 12-month-old kidneys). Scale bars, $50 \mu \mathrm{m}(\mathbf{A}-\mathbf{H}) ; 20 \mu \mathrm{m}(\mathbf{I}-\mathbf{N})$. cy, cyst.

and $\mathrm{M}$, respectively), liver (Figure 3, $\mathrm{H}, \mathrm{N}$ versus I and $\mathrm{O}$, respectively), and pancreas (Figure $3, \mathrm{~J}$ and $\mathrm{P}$ versus $\mathrm{K}$ and $\mathrm{Q}$, respectively) was stronger than in the wild-type controls, indicating that human PC2 could be greatly restored in the kidney, liver, and pancreas in $P k d 2$-null mice, and that embryonic lethality in $P k d 2$-null mice could be prevented by human PC2 reexpression. To further validate this finding,
Kaplan-Meier survival analysis between wild-type and $P k d 2^{-I-} ; P K D 2^{\mathrm{tg}}$ mice was performed. The $P k d 2^{-/-} ; P K D 2^{\mathrm{tg}}$ mice were born at a frequency of $28.6 \%(n=70)$, similar to the expected Mendelian ratio, supporting that the $P K D 2$ transgene could fully rescue the embryonic lethality in the $P k d 2$-null mice. However, the median survival time in the $P k d 2^{-1-} ; P K D 2^{\text {tg }}$ mice was only up to 6 months of age (Figure 3R), 

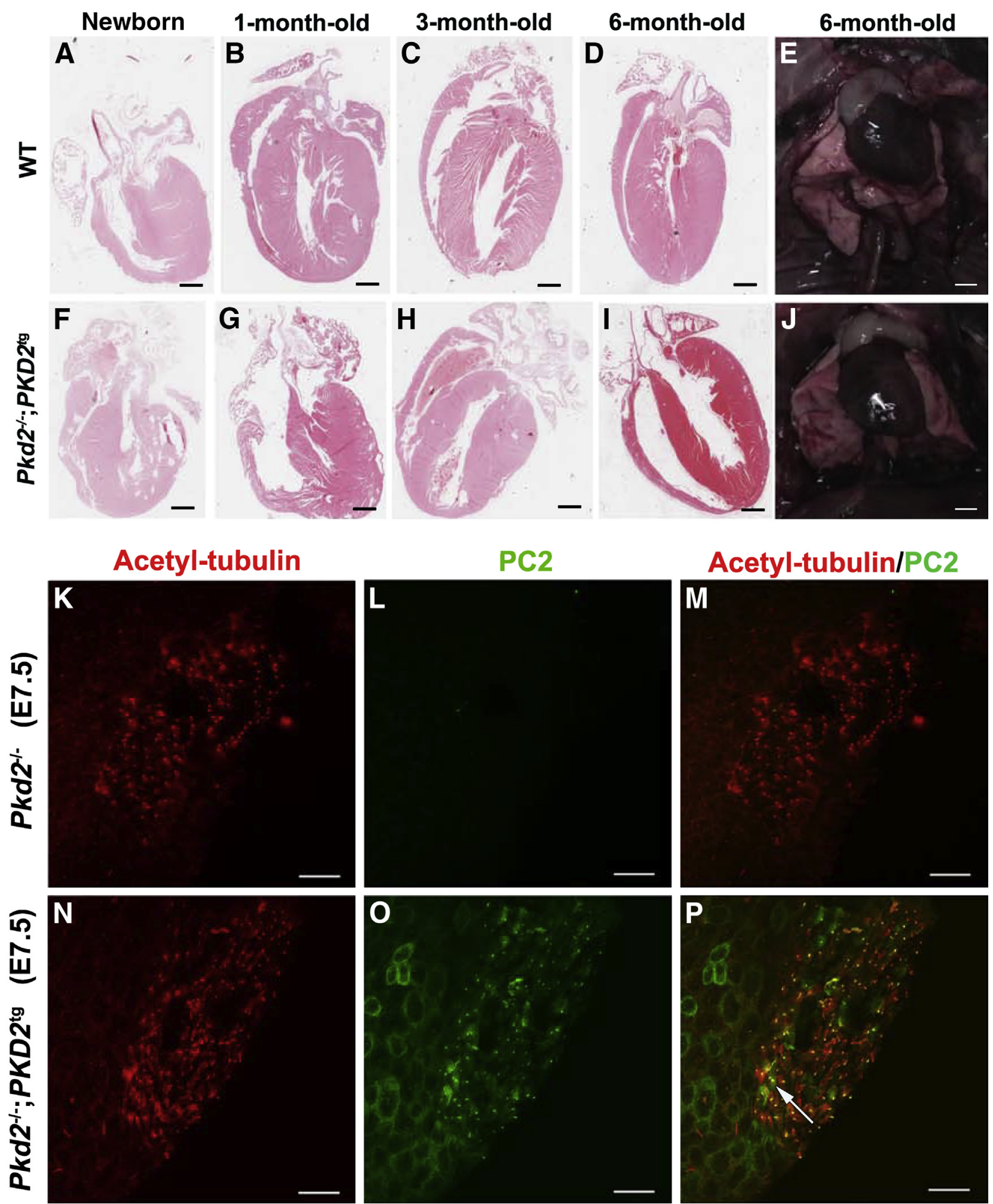

Figure 6 Rescue of cardiac septum defects in Pkd2-null mice by the expression of human polycystin (PC)-2. A-J: Compared to age-matched wild-type (WT) mice (A-D), no abnormal ventricular or atrial septa are found in the newborn (F) or the 1- (G), 3- (H), or 6-month-old (I) heart of $P k d 2$-null mice with a hemizygous $P K D 2$ transgene $\left(P k d 2^{-/-} ; P K D 2^{\mathrm{tg}}\right)$, respectively. All of the $P k d 2^{-/-} ; P K D 2^{\mathrm{tg}}$ mice tested had a heart in which the apex pointed to the left (levocardia), consistent with wild-type mice (E and J). K-P: Polycystin (PC)-2 re-expression in cilia at the embryonic node. Cilia at the embryonic nodes of embryonic days (E) $7.5 \mathrm{Pkd}^{-/-}$and $P k d 2^{-/-} ; P K D 2^{\text {tg }}$ mice were co-stained by an anti-acetylated tubulin antibody (K) and an anti-PC2 polyclonal antibody (L). The merged image (M) shows there is only acetylated tubulin staining (red) in the node cilia of E7.5 Pkd2 ${ }^{-1-}$ mice. By the same staining (N-P), PC2 (green) can be re-expressed in cilia at the embryonic node of E7.5 $P k d 2^{-/-} ; P K D 2^{\text {tg }}$ mice (arrow). $n=5\left(\mathbf{A}-\mathbf{J}\right.$, each age of wild-type or $\left.P k d 2^{-/-} ; P K D 2^{\mathrm{tg}}\right)$. Scale bars: $1.6 \mathrm{~mm}(\mathbf{A}$ and $\mathbf{F}) ; 1.3 \mathrm{~mm}$ (B and $\mathbf{G}) ; 0.8 \mathrm{~mm}(\mathbf{C}, \mathbf{D}, \mathbf{H}$ and $\mathbf{I}) ; 3 \mathrm{~mm}(\mathbf{E}$ and $\mathbf{J}) ; 50 \mu \mathrm{m}(\mathbf{K}-\mathbf{P})$. 
A

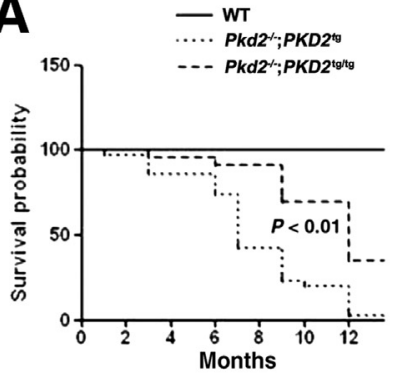

B $\quad$ wT

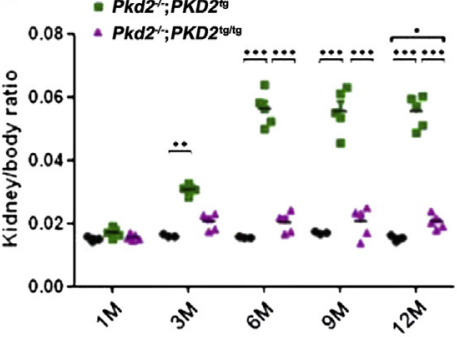

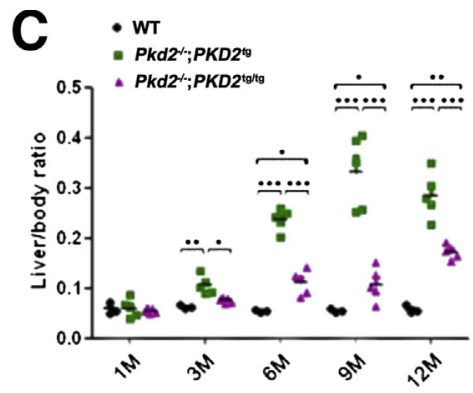
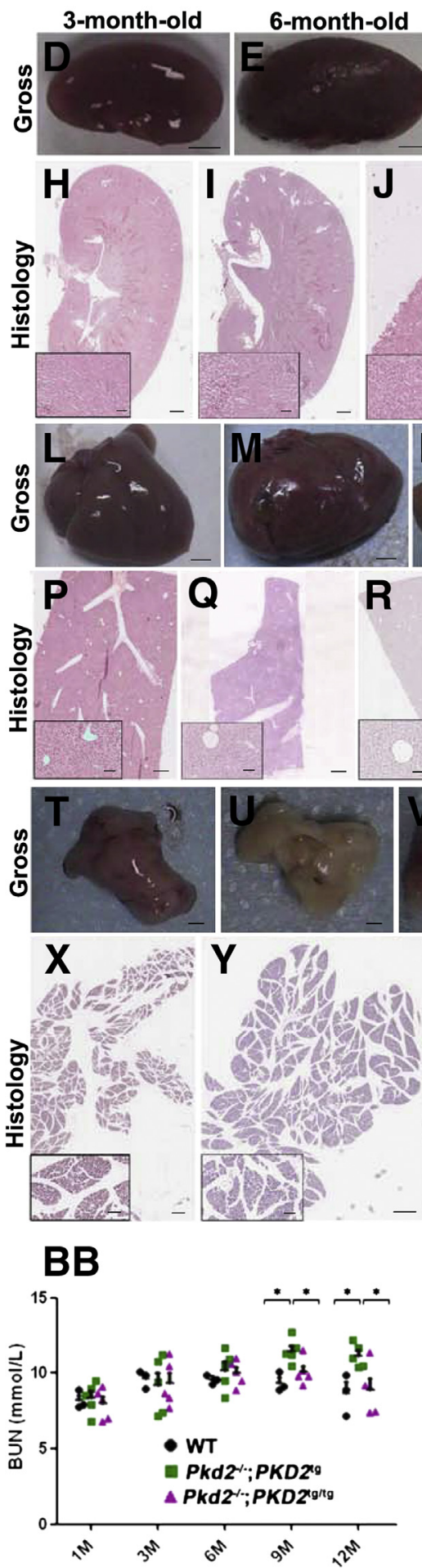

\section{6-month-old}
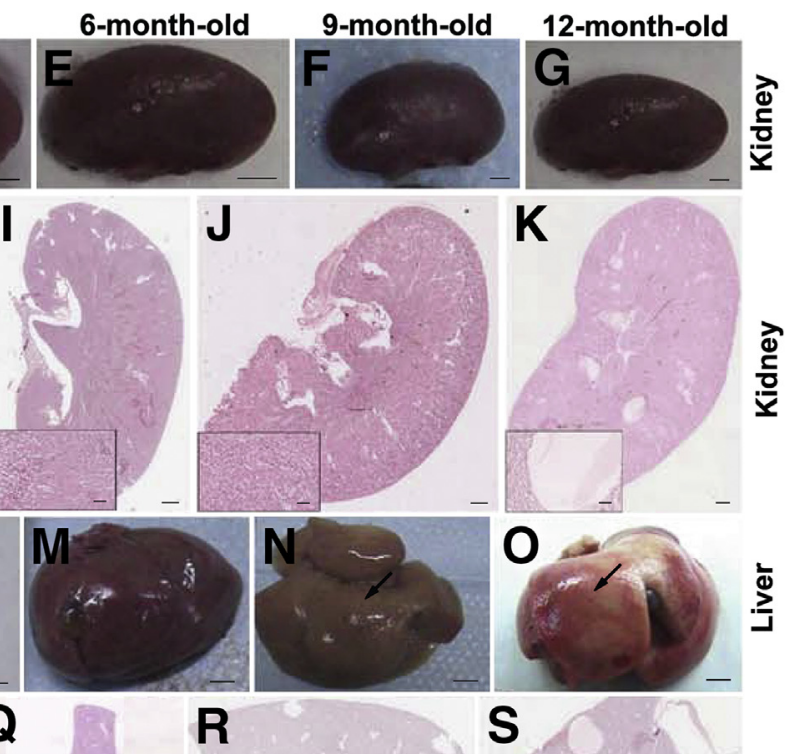

S

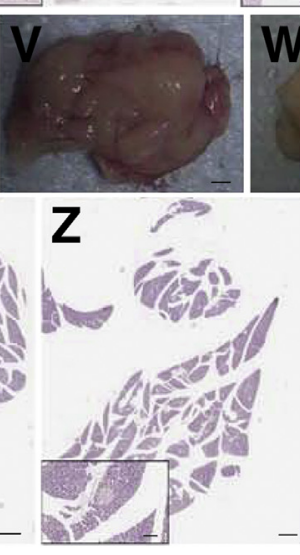

\section{CC}

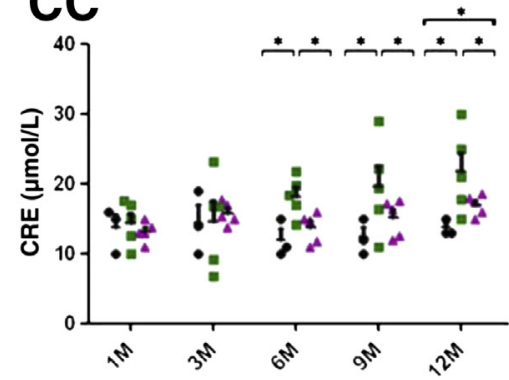

Figure 7 Allelic increase in the PKD2 transgene remarkably improves the prognosis of $P k d 2$-deficient mice. A: Kaplan-Meier survival analysis of wild-type (WT), ఫे $P k d 2^{-1-} ; P K D 2^{\mathrm{tg}}$, and $P k d 2^{-1-} ; P K D 2^{\mathrm{tg} / \mathrm{tg}}$ mice. $P k d 2-$ null mice with homozygous PKD2 transgenes $\left(P_{k d 2^{-I}}\right.$; $\left.P K D 2^{\mathrm{tg} / \mathrm{tg}}\right)$ show a much higher survival rate than $P k d 2-$ null mice with the hemizygous $P K D 2$ transgene $\left(P k d 2^{-/-}\right.$; $\left.P K D 2^{\mathrm{tg}}\right)$. Median survival rate of the $P k d 2^{-/} ; P K D 2^{\mathrm{tg} / \mathrm{tg}}$ mice is approximately 12 months, whereas that of $P \mathrm{kd}^{-/-}$; $P K D 2^{\text {tg }}$ mice is around 6 months. B: Kidney/body ratio (kidney index) of 1-, 3-, 6-, 9-, and 12-month-old wild-type, $P k d 2^{-1-} ; P K D 2^{\mathrm{tg}}$, and $P k d 2^{-1-} ; P K D 2^{\mathrm{tg} / \mathrm{tg}}$ mice. C: Liver/ body ratio (liver index) of the same mice. D-AA: Cystic phenotypes in the $P k d 2^{-/-} ; P K D 2^{\mathrm{tg} / \mathrm{tg}}$ kidney, liver, and pancreas. No obvious gross cysts are found in the $P k d 2^{-/}$; $P K D 2^{\text {tg/tg }}$ kidneys up to the age of 12 months $(\mathbf{D}-\mathbf{G})$. Histological analysis reveals similar findings $(\mathbf{H}-\mathbf{K})$, but sporadic histological cysts are found in the kidney of 12-month-old $P k d 2^{-1-} ; P K D 2^{\text {tg/tg }}$ mice (K). No gross cysts are seen in the 3- and 6-month-old liver ( $\mathbf{L}$ and $\mathbf{M})$, but they are seen in the 9- and 12-month-old liver (arrows) ( $\mathbf{N}$ and $\mathbf{0}$ ). Histological examination reveals cystic lesions in the $P k d 2^{-I-} ; P K D 2^{\text {tg/tg }}$ liver at 6 months $(\mathbf{Q})$, and the cystic phenotype worsens with age ( $\mathbf{R}$ and $\mathbf{S})$. There are no obvious gross or histological cysts in the pancreas of these mice (T-AA). High-power images of the boxed areas are shown in the lower-left corners. BB: Blood urea nitrogen (BUN) levels of 1-, 3-, 6-, 9-, and 12-month-old wild-type, $P k d 2^{-1-} ; P K D 2^{\text {tg }}$, and $P k d 2^{-1-} ; P K D 2^{\text {tg/tg }}$ mice. Significantly higher elevations are detected in the 9- and 12-month-old $P k d 2^{-I-} ; P K D 2^{\text {tg }}$ mice compared to age-matched wild-type and $P k d 2^{-/-} ; P K D 2^{\mathrm{tg} / \mathrm{tg}}$ mice, respectively. There is no significant difference between the BUN levels in wild-type and $P k d 2^{-1-} ; P K D 2^{\text {tg/tg }}$ mice. CC: Similar findings are obtained in the creatinine (CRE) analysis of the same mice. However, a significant difference between the CRE levels of wild-type and $P k d 2^{-/-} ; P K D 2^{\mathrm{tg} / \mathrm{tg}}$ mice is found only at the age of 12 months. ${ }^{*} P<0.05,{ }^{* *} P<0.01$, and ${ }^{* * *} P<0.001 . n=3$ (B, wild-type); $n=5$ (B, Pkd2 $2^{-1-} ; P K D 2^{\text {tg }}$ and $P k d 2^{-1-}$; $P K D 2^{\mathrm{tg} / \mathrm{tg}} ; \mathbf{D}-\mathbf{A A}$, each age); $n=25$ (A, wild-type and $\left.P k d 2^{-/-} ; P K D 2^{\mathrm{tg}}\right) ; n=40\left(\mathbf{A}, P k d 2^{-/-} ; P K D 2^{\mathrm{tg} / \mathrm{tg}}\right)$. Scale bars: $2 \mathrm{~mm}(\mathbf{D}-\mathbf{G}) ; 4 \mathrm{~mm}(\mathbf{L}-\mathbf{0}) ; 1 \mathrm{~mm}(\mathbf{T}-\mathbf{W}) ; 500 \mu \mathrm{m}$ (H-K, P-S, X-AA); $100 \mu \mathrm{m}$ (insets). M, months. 
suggesting that these mice might still die from the disease phenotype.

To investigate the phenotype, we examined $P k d 2^{-/-} ; P K D 2^{\text {tg }}$ mice by gross and histological analyses. On gross examination, almost no cysts could be seen in the kidneys (Figure 4A) or liver (Figure $4 \mathrm{I}$ ) in the $P k d 2^{-/-} ; P K D 2^{\text {tg }}$ mice up to the age of 3 months, or in the pancreas before 12 months (Figure 4, Q-T). However, gross cysts were observed in the kidney (Figure 4, A versus $\mathrm{B}-\mathrm{D}$ ) and liver (Figure 4, I versus $\mathrm{J}-\mathrm{L}$ ) starting at 6 months. Histological analysis revealed findings similar to those of the gross examination, with the cystic progression in the $P k d 2^{-/-} ; P K D 2^{\text {tg }}$ mice worsening with age (Figure 4, $\mathrm{E}-\mathrm{H}, \mathrm{M}-\mathrm{P}$, and $\mathrm{U}-\mathrm{X})$. These results suggested that the $P k d 2^{-/} ; P K D 2^{\text {tg }}$ mice could still develop progressive cyst formation in the kidneys, although the transgenically expressed human PC2 was able to significantly suppress the cystogenesis in $P k d 2$-deficient mice.

We next investigated the nephron-segment origin of the renal cysts in the $P k d 2^{-1-} ; P K D 2^{\text {tg }}$ mice using nephronspecific markers: Lotus tetragonolobus lectin for the proximal tubule, antibody to Tamm-Horsfall glycoprotein for the medullary thick ascending limb of the loop of Henle and distal convoluted tubules, and Dolichos biflorus agglutinin and anti-aquaporin-2 antibody for the collecting ducts. The staining results revealed that although some obvious dilated tubules were from the proximal portion of the nephron (Figure 5, A and E), the large renal cysts of the aged $P k d 2^{-/-}$; $P K D 2^{\mathrm{tg}}$ mice were mostly derived from the distal tubules (Figure 5, B and F) and collecting ducts of the nephron (Figure 5, $\mathrm{C}$ and $\mathrm{G}$ and $\mathrm{D}$ and $\mathrm{H}$ ). These findings indicate that the renal cysts in the $P k d 2^{-1} ; P K D 2^{\mathrm{tg}}$ mice were derived from all parts of the nephron segment but predominated in the distal parts of the nephron, as has previously been reported. ${ }^{16,28}$

To confirm that cyst progression was retarded by reexpression of human PC2 in the $P k d 2^{-/-} ; P K D 2^{\text {tg }}$ kidney, we used our previously generated $P k d 2$ conditional knockout mice $\left(P k d 2^{\mathrm{f} 3 / \mathrm{f3}}\right)^{23}$ to cross with the Nestin-Cre transgenic mice, in which Cre expression was widely initiated in the kidneys at E15.5. ${ }^{29-31}$ Resulting Nestin-Cre; $P k d 2^{\mathrm{f3} / \mathrm{f3}}$ mice were then mated with $P K D 2^{\mathrm{tg}}$ to produce Nestin-Cre; $P k d 2^{\mathrm{f} 3 / \mathrm{f3}} ; P K D 2^{\mathrm{tg}}$ mice. Compared to similarly high PC2 expression in the 1-month-old Nestin-Cre; $P k d 2^{\mathrm{f} 3 / \mathrm{f3}} ; P K D 2^{\mathrm{tg}}$ kidney (Figure 5, $\mathrm{I}-\mathrm{K})$, variable and significant absence of $\mathrm{PC} 2$ expression was seen in Lotus tetragonolobus lectin-positive nephron segments of the same aged Nestin-Cre; $P k d 2^{\mathrm{f} / \mathrm{f3} 3}$ kidneys (Figure 5, L-N). Findings were similar in the TammHorsfall glycoprotein- and aquaporin-2/Dolichos biflorus agglutinin-positive tubules of the tested kidneys (data not shown). Immunofluorescence staining indicated that $P k d 2$ deficient mice with $P K D 2^{\text {tg }}$ reexpressed $\mathrm{PC} 2$ in diverse renal tubules, by which renal cyst might be largely ameliorated.

Collectively, these results demonstrate that functional restoration by the human $P K D 2$ transgene could rescue embryonic lethality in $P k d 2$-null mice and significantly postpone the onset of ADPKD phenotypes.
Human PC2 Rescues Cardiac Septum and Left-Right Determination Defects in Pkd2-Null Mice

Previous studies showed that $P k d 2$-null embryos exhibit cardiac septum defects and abnormal laterality, which manifests as situs inversus involving the stomach, liver, lung, spleen, and pancreas. ${ }^{21,32,33}$ To explore whether transgenic restoration of PC2 could rescue these abnormal phenotypes, we examined the cardiac and left-right axis development in the $P k d 2^{-/-} ; P K D 2^{\text {tg }}$ mice. There were no laterality defects in the 1-month-old $P k d 2^{-/-} ; P K D 2^{\text {tg }}$ mice examined (Figure 6, A-J and Supplemental Table S1). In addition, the interventricular septum and atrial septum were also histologically normal in the same mice examined (Figure 6, A-D and F-I). The laterality defects associated with $P k d 2$ knockouts have previously been attributed to the absence of PC2 expression in the cilia of the embryonic node, which are usually considered to be involved in establishing the left-right axis. ${ }^{34}$ The finding that no surviving mice showed any laterality defects, coupled with our observation that there was no embryonic or perinatal lethality in the transgenically rescued null animals, suggests that $P K D 2^{\mathrm{tg}}$ efficiently expressed $\mathrm{PC} 2$ cilia in the embryonic node. We investigated this hypothesis directly by examining PC2 expression in the embryonic node in E7.5 $P k d 2^{-1-}$ and $P k d 2^{-l-} ; P K D 2^{\mathrm{tg}}$ mice. We confirmed that $\mathrm{PC} 2$ was absent in the embryonic node in E7.5 $P k d 2^{-1-}$ mice (Figure 6, $\mathrm{K}-\mathrm{M}$ ) and found that $\mathrm{PC} 2$ expression was indeed restored in cilia at the embryonic node in E7.5 $P k d 2^{-1-} ; P K D 2^{\text {tg }}$ mice (Figure 6, N-P). In general, these results indicate that the cardiac and laterality defects in the $P k d 2$-null mice are restored by functional expression of the human PKD2 transgene.

\section{Kidney and Liver Cysts in Pkd2-Deficient Mice Are Significantly Ameliorated by a Transgene Dosage-Dependent Effect}

Although embryonic lethality in the $P k d 2$-null mice was fully rescued by the human PKD2-transgene allele $\left(P k d 2^{-l-} ; P K D 2^{\mathrm{tg}}\right)$, these mice still developed widespread cystic kidneys and liver by the age of 9 months (Figure 4, G and $\mathrm{H}$, and $\mathrm{O}$ and $\mathrm{P}$ ). We hypothesized that increasing the level of functional PC2 expression might further ameliorate the cystic phenotypes and improve prognosis in the $P k d 2$-deficient mice.

Using an approach similar to that described in Figure 2A, we obtained $P k d 2$-null mice with homozygous $P K D 2$-transgene alleles (ie, $P k d 2^{-/-} ; P K D 2^{\mathrm{tg} / \mathrm{tg}}$ ). Kaplan-Meier analysis revealed that approximately $90 \%$ of the $P k d 2^{-l-} ; P K D 2^{\text {tg/tg }}$ mice survived beyond 8 months, whereas $<50 \%$ of the $P k d 2^{-1-} ; P K D 2^{\text {tg }}$ mice survived past this age $(P<0.01)$. Furthermore, approximately $50 \%$ of the $P k d 2^{-l-} ; P K D 2^{\text {tg } / \mathrm{gg}}$ mice survived for 12 months, whereas only $5 \%$ of the $P k d 2^{-1-} ; P K D 2^{\text {tg }}$ mice survived $(P<0.01)$ (Figure $7 \mathrm{~A}$ ). These results indicate that the double-allelic restoration of 
Li et al

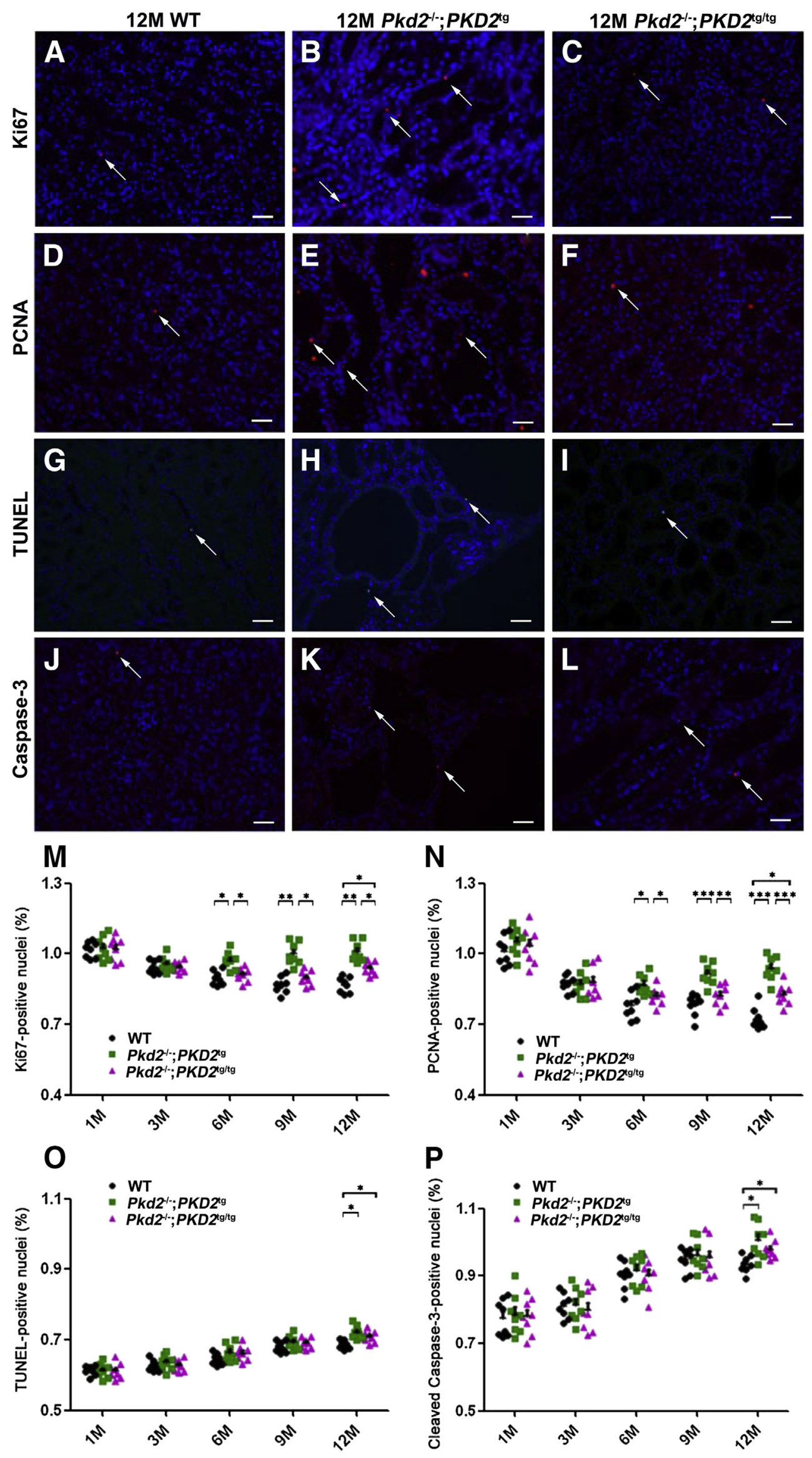

2854

ajp.amjpathol.org - The American Journal of Pathology 
the human $P K D 2$ transgene markedly improved survival in $P k d 2$-deficient mice.

To evaluate the disease severity between the $P k d 2$-null mice with single $P K D 2^{\mathrm{tg}}$ - and double $P K D 2^{\mathrm{tg} / \mathrm{tg}}$-transgene alleles, we examined the kidney/body weight and liver/body weight ratios as kidney and liver indexes. Significant differences in kidney and liver indexes in the $P k d 2^{-1-} ; P K D 2^{\text {tg }}$ mice compared to those in wild-type mice began to occur at 3 months of age. However, the $P k d 2^{-1-} ; P K D 2^{\text {tg/tg }}$ mice showed significant differences in the kidney index at 12 months $(P<0.05)$ and in the liver index at 6 months $(P<0.05)$ (Figure 7, B and C). These results indicate that the double-transgene alleles still could not fully rescue kidney and liver indexes to normal levels, although cystic progression was much milder in the $P k d 2^{-/-} ; P K D 2^{\mathrm{tg} / \mathrm{tg}}$ mice than in the $P k d 2^{-/-} ; P K D 2^{\mathrm{tg}}$ mice.

We also compared the cystic phenotypes of the disease-affected organs between the $P k d 2^{-1-} ; P K D 2^{\text {tg }}$ and $P k d 2^{-1-} ; P K D 2^{\mathrm{tg} / \mathrm{tg}}$ mice. We examined the kidney, liver, and pancreas in the mice at 1, 3, 6, 9, and 12 months of age ( $n=5$ per age group). Strikingly, no obvious gross cysts were observed in the kidneys (Figure $7, \mathrm{D}-\mathrm{G}$ ) or pancreas (Figure $7, \mathrm{~T}-\mathrm{W}$ ) in the $P k d 2^{-l-} ; P K D 2^{\text {tg/tg }}$ mice up to the age of 12 months. There was also no obvious gross cysts in the mouse liver until the age of 6 months (Figure 7, L and M), but small gross cysts were observed in the liver in $P k d 2^{-1-} ; P K D 2^{\mathrm{tg} / \mathrm{tg}}$ mice at and after 9 months (Figure 7, $\mathrm{N}$ and $\mathrm{O}$ ). Histological analysis showed findings similar to those of the gross examination; that is, no obvious microscopic cysts were found in the kidneys (Figure 7, H-J) or pancreas (Figure 7, $\mathrm{X}-\mathrm{AA})$ in the $P k d 2^{-1-} ; P K D 2^{\mathrm{tg} / \mathrm{tg}}$ mice up to 9 and 12 months of age, respectively, although a small number of microscopic cysts were seen in the kidneys at 12 months (Figure $7 \mathrm{~K}$ ) and in the liver beyond 6 months (Figure 7, $\mathrm{Q}-\mathrm{S})$. Compared to the $P k d 2^{-l-} ; P K D 2^{\text {tg }}$ mice on cystic analysis (Figure 4), these results indicate that the homozygous $P K D 2$-transgene alleles almost fully rescued the cystic phenotypes in ADPKD mice in a transgene dosedependent manner, but also point to the existence of some non-kidney-related factors in the reduced survival in transgenically rescued $P k d 2$-null animals.

In addition, we investigated the renal phenotype of Nestin$\mathrm{Cre} ; P k d 2^{\mathrm{f} 3 / \mathrm{f3}}$ mice with and without human $P K D 2^{\mathrm{tg}}$ allele(s). By gross and histological analyses, a finding similar to that in the $P k d 2^{-/-} ; P K D 2^{\text {tg }}$ kidneys (Figure 4 ) could be seen in the kidneys in Nestin-Cre; $P k d 2^{\mathrm{f} 3 / \mathrm{f3}} ; P K D 2^{\mathrm{tg}}$ and Nestin$\mathrm{Cre} ; P k d 2^{\mathrm{f} 3 / f 3} ; P K D 2^{\mathrm{tg} / \mathrm{tg}}$ mice (Supplemental Figure $\mathrm{S} 3$ ). The results provided the further evidence that the transgenically expressed human PC2 was able to significantly suppress cystogenesis in $P k d 2$-deficient mice.

To assess the functional manifestations of progressive cystic disease, we examined renal function-related indictors: serum BUN and CRE. We found that the BUN and CRE levels were significantly elevated, and worsened with age, in the $P k d 2^{-l-} ; P K D 2^{\text {tg }}$ mice compared with those in the age-matched wild-type mice (Figure 7, BB and CC). Notably, the elevated BUN and CRE levels in the $P k d 2^{-1-} ; P K D 2^{\text {tg }}$ mice were significantly improved in the $P k d 2^{-1-} ; P K D 2^{\mathrm{tg} / \mathrm{tg}}$ mice. Except for the CRE level at 12 months (Figure 7CC), the BUN and CRE levels in the $P k d 2^{-1-} ; P K D 2^{\text {tg/tg }}$ mice were rescued to the normal levels of the age-matched wild-type mice, suggesting that the impaired renal function in the $P k d 2^{-l-} ; P K D 2^{\text {tg }}$ mice was correlated with the improvement in polycystic disease severity with the addition of another PKD2-transgene allele.

\section{Abnormal Proliferation in the Cystic Kidneys Is Rectified by the Restoration of Functional PC2}

Previous studies have demonstrated that renal cyst formation is closely associated with aberrant proliferation and apoptosis, ${ }^{35-38}$ that abnormal cell proliferation is a major feature of the cystic kidneys in $\mathrm{ADPKD},{ }^{39}$ and that loss of the ADPKD causal gene products, $\mathrm{PC} 1$ and $\mathrm{PC} 2$, results in increased proliferation and/or increased apoptosis of renal epithelial cells in vivo and in vitro. ${ }^{31,40-44}$ Our previous study also indicated that PC2 loss increased cell proliferation and apoptosis in vitro. ${ }^{23} \mathrm{We}$ therefore determined whether abnormal proliferation or apoptosis was a major contributor to cystogenesis in ADPKD in the $P k d 2^{-1-}$; $P K D 2^{\text {tg }}$ and $P k d 2^{-I-} ; P K D 2^{\text {tg/tg }}$ model systems. We examined kidney sections from wild-type, $P K D 2^{\mathrm{tg}}, P K D 2^{\mathrm{tg} / \mathrm{tg}}$, $P k d 2^{-1-} ; P K D 2^{\mathrm{tg}}$, and $P k d 2^{-1-} ; P K D 2^{\mathrm{tg} / \mathrm{tg}}$ mice at different ages $(1,3,6,9$, and 12 months) for proliferation markers (Ki67 and PCNA) and apoptosis markers (TUNEL and cleaved Casp3). The results showed no statistical difference in proliferation or apoptosis between the wild-type mice and those with a single transgene (ie, $P K D 2^{\mathrm{tg}}$ ) or double transgenes (ie, $P K D 2^{\mathrm{tg} / \mathrm{tg}}$ ) alone (data not shown). However, increased labeling of proliferation markers was seen in the $P k d 2^{-l-} ; P K D 2^{\text {tg }}$ kidneys compared to wild-type kidneys from the age of 6 months (Figure 8, A-F, M and N), whereas

\footnotetext{
Figure 8 Allelically increased PC2 expression prevents excessive cell proliferation in the cystic kidneys of $P k d 2$-deficient mice. A-L: Proliferation and apoptosis status of 12 -month-old wild-type (WT), $P k d 2^{-/-} ; P K D 2^{\mathrm{tg}}$, and $P k d 2^{-/-} ; P K D 2^{\mathrm{tg} / \mathrm{tg}}$ mice were analyzed by immunofluorescence staining. Proliferation markers Ki-67 and proliferating cell nuclear antigen (PCNA) (arrows in A-F) re detected to assess the proliferation rate in the kidneys of wild-type, $P k d 2^{-/-} ; P K D 2^{\mathrm{tg}}$, and $P k d 2^{-/-} ; P K D 2^{\mathrm{tg} / \mathrm{tg}}$ mice. Apoptosis was assessed by terminal deoxynucleotidyl transferase dUTP nick end labeling (TUNEL) and anti-cleaved caspase-3 antibody (arrows) staining in the same mice $(\mathbf{G}-\mathbf{L})$. $\mathbf{M}$ and $\mathbf{N}$ : Significantly elevated proliferation rates are found between the kidneys of wild-type and $P k d 2^{-1-} ; P K D 2^{\text {tg }}$ mice starting at the age of 6 months, and these increased rates are significantly suppressed by allelically increasing the number of $P K D 2$ transgenes ( $n=8$ per genotype). $\mathbf{0}$ and $\mathbf{P}$ : The same kidneys were analyzed for apoptosis markers. Significantly different apoptosis is detected only between the kidneys of 12 -month-old wild-type and $P k d 2^{-/-} ; P K D 2^{\text {tg }}$ or $P k d 2^{-/-} ; P K D 2^{\mathrm{tg} / \mathrm{tg}}$ mice. ${ }^{*} P<0.05$, ${ }^{* *} P<0.01$, and $* * * P<0.001$. Scale bar $=60 \mu \mathrm{m}(\mathbf{A}-\mathbf{L}) . \mathbf{M}$, months.
} 
A

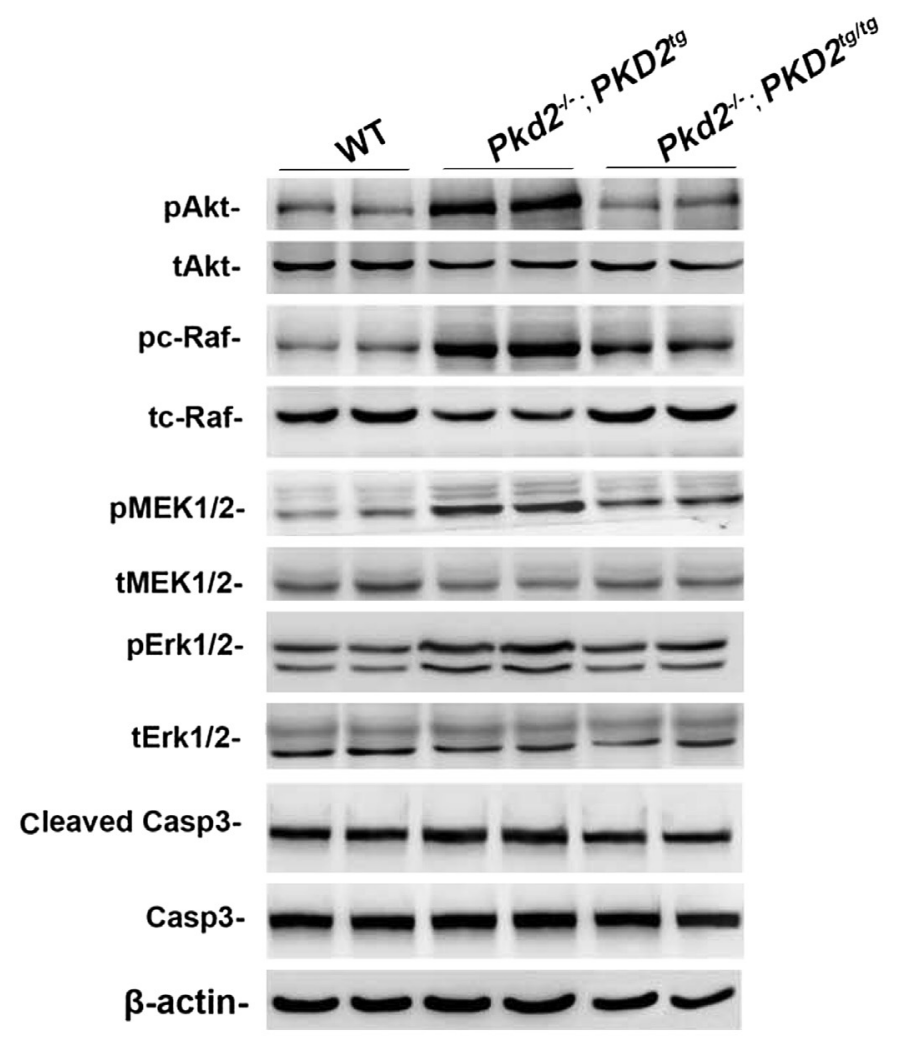

D

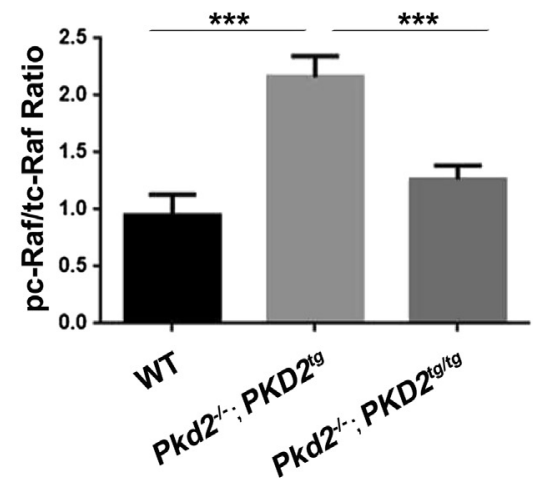

E

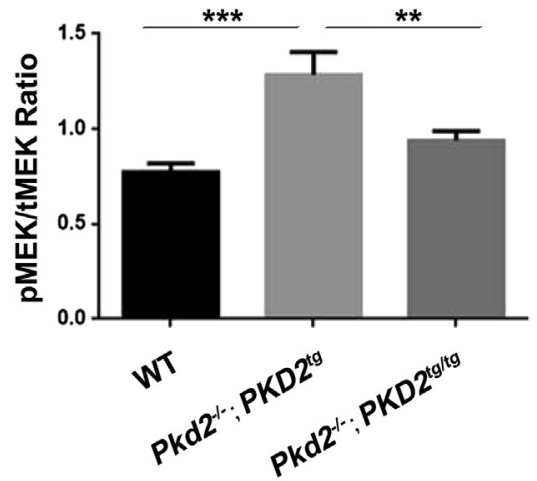

B

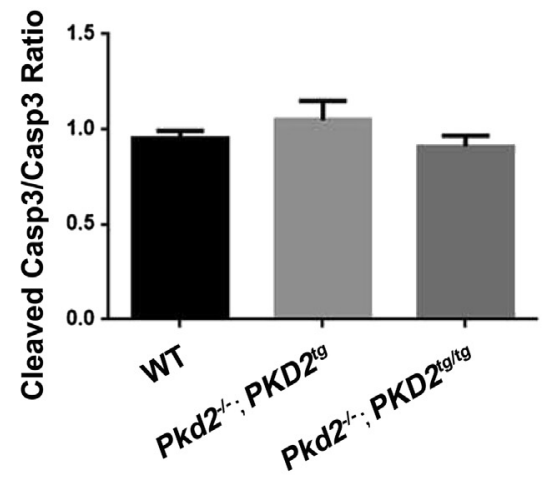

C

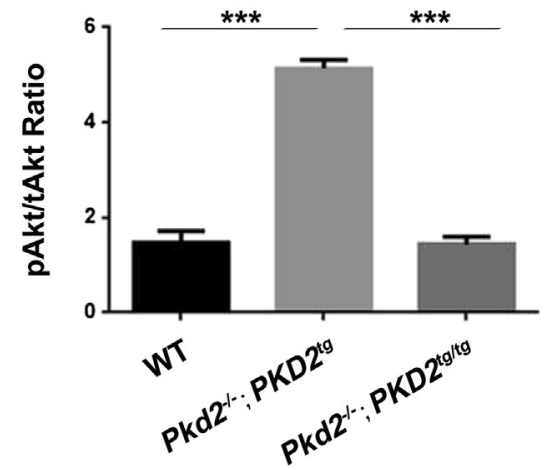

$\mathbf{F}$

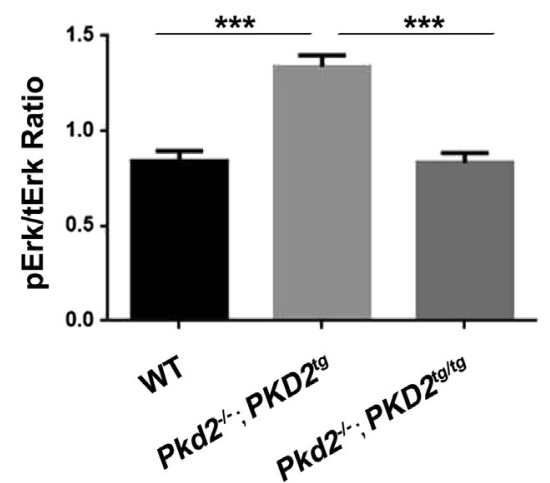

Figure 9 Polycystin (PC)-2 deficiency significantly up-regulates the Akt/MAPK signaling pathway. A: Duplicated protein lysates from the 9-month-old kidneys were immunoblotted with antibodies to phospho-Akt (pAkt) and total Akt (tAkt); phospho-c-serine/threonine-protein kinase (pc-Raf) and total c-Raf (tc-Raf); phospho- marker extraction kernel (pMEK)-1/2 and total MEK1/2 (tMEK1/2); and phospho-Erk1/2 (pErk1/2) and total Erk1/2; cleaved caspase (Casp)-3 and Casp3; $\beta$-actin (a protein-loading control). B: A normalized quantitative analysis was performed using the densitometry values from the Western blots for cleavedcasp3/casp3. Other normalized quantitative analyses of the densitometry values of pAkt/tAkt (C), pc-Raf/tc-Raf (D), pMEK1/2/tMEK1/2 (E), and pErk1/2/tErk1/2 (F) were also performed. Compared to the age-matched wild-type (WT) kidneys, the statistical analysis indicates significant up-regulation of Akt and its downstream factors in the $P k d 2^{-/-} ; P K D 2^{\text {tg }}$ kidneys, but not in $P k d 2^{-/-} ; P K D 2^{\operatorname{tg} / \operatorname{tg}}$ kidneys. Data expressed as means $\pm \mathrm{SD}(\mathbf{B}-\mathbf{F}){ }^{* *} P<0.01,{ }^{* * *} P<0.001$.

minimally increased apoptosis labeling was observed only at the age of 12 months (Figure 8, G-L, O and P). The increased proliferation rate in the $P k d 2^{-1-} ; P K D 2^{\text {tg }}$ kidneys was significantly reduced by the additional $P K D 2$-transgene allele (ie, $P k d 2^{-1-} ; P K D 2^{\mathrm{tg} / \mathrm{tg}}$ ), whereas the apoptosis rate was not (Figure 8, M-P). Notably, although the abnormal proliferation in the $P k d 2^{-I-} ; P K D 2^{\text {tg }}$ kidneys fully recovered to the wild-type level in the $P k d 2^{-l-} ; P K D 2^{\mathrm{tg} / \mathrm{tg}}$ kidneys at 6 and 9 months, there was still a significant difference at 12 months between the wildtype and $P k d 2^{-l-} ; P K D 2^{\text {tg/tg }}$ kidneys $(P<0.05)$ (Figure $8, \mathrm{M}$ and $\mathrm{N}$ ), suggesting that normal proliferation could not be fully restored in $P k d 2$-null mice with the homozygous transgene alleles. An increased apoptosis rate was observed in only the 12-month-old $P k d 2^{-/-} ; P K D 2^{\text {tg }}$ kidneys $(P<0.05)$, but this 
Table 1 Allelic Human PKD2 Transgene Restoration in $P k d 2^{-/-}$Mice

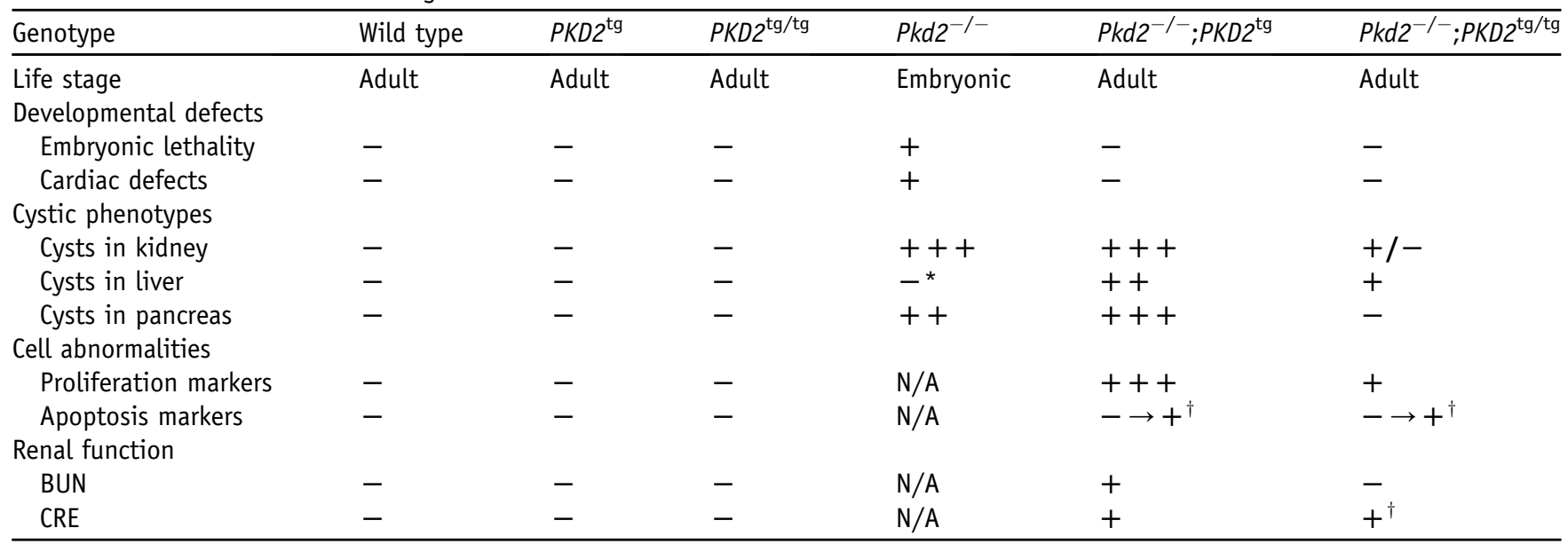

${ }^{*}$ No liver cysts occur in embryonic stage.

${ }^{\dagger}$ Only at 12 month of age.

- , negative/normal; + , positive/abnormal $(+++$, very severe; ++ , severe; + , obvious; \pm , few); BUN, blood urea nitrogen; CRE, creatinine; N/A, not applicable.

increased rate was not rescued by the allelic increase in $\mathrm{PC} 2$ (Figure 8, $\mathrm{O}$ and $\mathrm{P}$ ).

To investigate the molecular mechanism by which the restoration of human $\mathrm{PC} 2$ affected proliferation and apoptosis, we used Western blot analyses to examine the apoptotic marker Casp3 and the proliferation-related markers Akt, serine/ threonine-protein kinase (c-Raf), mitogen-activated protein kinases (MEK), and extracellular-signal-regulated kinases (Erk), which have been recognized in many other studies, ${ }^{35-38,41-44}$ in the 9-month-old wild-type, $P k d 2^{-1-}$; $P K D 2^{\text {tg }}$, and $P k d 2^{-1-} ; P K D 2^{\text {tg/tg }}$ kidneys. Consistent with the apoptotic finding in Figure 8, G-L, O and $\mathrm{P}$, there was no significant difference in the levels of the cleaved Casp3 expression (Figure 9, A and B). However, Western blot results showed that the $P k d 2^{-1-} ; P K D 2^{\text {tg }}$ kidney exhibited significant up-regulation of phosphorylated Akt, c-Raf, MEK, and Erk expression (Figure 9, A and $\mathrm{C}-\mathrm{F}$ ), indicating that insufficient reexpression of $\mathrm{PC} 2$ significantly elevated all proliferationassociated markers via the dysregulation of Akt phosphorylation and its downstream factors. Interestingly, abnormally elevated expression of these proliferative markers could be recovered to wild-type levels by allelic PC2 increase (Figure 9, $\mathrm{C}-\mathrm{F})$. Correlated with the finding of massive cysts in the $P k d 2^{-1-} ; P K D 2^{\text {tg }}$ kidney (Figure 4), but not in the $P k d 2^{-1-}$; $P K D 2^{\mathrm{tg} / \mathrm{tg}}$ kidneys (Figure 7), the results indicate that cystogenesis might result from dysregulation of the Akt/c-Raf/MEK/ Erk cascade, which may be the molecular mechanism underlying the increased renal proliferation in ADPKD. In aggregate, the data support the hypothesis that proliferation, but not apoptosis, plays a crucial role in cystogenesis in ADPKD.

\section{Discussion}

In recent years, considerable advances have been made in elucidating the cellular and molecular mechanisms underlying the pathogenesis of ADPKD. ${ }^{2,14,37,42,45-50}$ However, there is still no effective therapy for this disease, and the prognosis for ADPKD patients has not substantially improved. Currently, a number of drugs targeting diverse cell signaling pathways that lead to abnormal cell proliferation, apoptosis, and fluid secretion are being studied in preclinical and clinical trials, but only a few show promise in slowing renal cyst progression, and their clinical application is still uncertain. $^{3,51-53}$ Therefore, more therapeutic strategies that could lead to new drugs or therapeutic interventions for ADPKD are desired.

To this end, we proposed to use the human PKD2 transgene in mouse mutant models for $P k d 2 .^{21,23}$ The mouse homologue of human PKD2 has been cloned and mapped to mouse chromosome 5. ${ }^{54}$ The mouse $P k d 2$ cDNA sequence is $5134 \mathrm{bp}$ long and is predicted to encode a 966-amino-acid integral membrane protein. There is overall high conservation within the coding regions of the mouse and human genes, with $87 \%$ identity at the nucleotide level and $91 \%$ identity and $98 \%$ similarity at the amino acid level. Both human and mouse PC2 proteins are also greatly conserved, including all structure and functional domains. We therefore attempted to use mouse mutant models for $P k d 2$ as a platform to explore the use of causal gene replacement in treating mouse ADPKD and tested whether the human $P K D 2$ transgene would also have a clinical value in treating ADPKD patients.

In this study, we investigated the effects of reexpression of human PC2 using a generalized, heterologous promoter construct. Systematic characterization of the $P K D 2^{\text {tg }}$ mice revealed that the ectopically overexpressed PC2 was widely detected in tissues. Nonetheless, there was no obvious abnormal phenotype in the mice with hemizygous $\left(P K D 2^{\mathrm{tg}}\right)$ or homozygous $\left(P K D 2^{\mathrm{tg} / \mathrm{tg}}\right)$ transgene alleles, suggesting that the overexpression of human PC2 in this model does not exert any deleterious effects during mouse development. 
Transgenic mouse models that overexpress the human orthologous PKD1 or PKD2 genes have been useful for understanding the pathogenesis of ADPKD. For PKD1 transgenic mice, some controversial results have been reported. Some mice with $P K D 1$ transgene exhibit cyst formation in the kidney, ${ }^{55,56}$ but some do not. ${ }^{57}$ In PKD2 transgenic mice, a similar situation can also be seen. A group reported a $P K D 2$ transgenic model in which human $P K D 2$ cDNA was used, but this $P K D 2$ transgenic model developed sporadic renal cysts over the age of 6 months. ${ }^{26}$ In addition, a $P K D 2$ bacterial artificial chromosome transgenic mice that show renal tubulopathy with pathological cysts/tubule dilation have been generated. ${ }^{27}$ However, in this study, our $P K D 2$-transgenic line exhibited no obvious cystic phenotype or any other disease defects up to 12 months of age, indicating that the appropriate heterologous overexpression of functional PC2 alone may not impair mouse embryogenesis or organogenesis. We surmised that some of the discordant findings in $P k d 2$-transgenic mice might be caused by transgene copy number and levels of functional PC2 expression.

$P k d 2$-null mice are known to die during embryogenesis. $^{21,32}$ In the present study, $P k d 2$-null mice with a hemizygous human $P K D 2$-transgene allele $\left(P k d 2^{-/-} ; P K D 2^{\text {tg }}\right)$ fully rescued the lethal phenotype, suggesting that the human PC2 was fully functional during mouse development. However, the adult $P k d 2^{-1-} ; P K D 2^{\text {tg }}$ mice still showed cyst formation in the kidney, liver, and pancreas. We therefore hypothesized that the cystic phenotypes were related to the level of functional PC2 expression, and deduced that allelic increase of the transgene would be beneficial to $P k d 2$-null mice. Consistent with the hypothesis, we found that mice with homozygous $P K D 2$-transgene alleles $\left(P K D 2^{\mathrm{tg} / \mathrm{tg}}\right)$ expressed $\mathrm{PC} 2$ at a level double that of the $P K D 2^{\mathrm{tg}}$ mice, and that the kidney and liver cysts seen in the $P k d 2^{-/-} ; P K D 2^{\text {tg }}$ mice almost disappeared in $P k d 2$-null mice with homozygous $P K D 2$-transgene alleles $\left(P k d 2^{-/-} ; P K D 2^{\mathrm{tg} / \mathrm{tg}}\right)$. In addition, the $P k d 2^{-1-} ; P K D 2^{\text {tg/tg }}$ mice also had a greater 12-month survival rate than the $P k d 2^{-1-} ; P K D 2^{\mathrm{tg}}$ mice. The finding that homozygous transgenic $P K D 2$ expression was associated with a better prognosis in an ADPKD model indicates that the disease phenotypes were rescued by the transgene in a dosedependent manner.

Increased proliferation and apoptosis were considered to be the primary driver for cyst growth in loss-of-function models based on the orthologous $P k d l$ and $P k d 2$ genes. ${ }^{3,44,58-60}$ Since $P k d 2^{-1-} ; P K D 2^{\text {tg }}$ produced more severe cystic phenotypes in the kidneys and liver than $P k d 2^{-/-} ; P K D 2^{\text {tg/tg }}$, we used our model system to examine whether decreased proliferation or apoptosis was most important for the reduction in cystogenesis with transgenic rescue in ADPKD. We observed increased proliferation in the $P k d 2^{-/-} ; P K D 2^{\text {tg }}$ kidney starting at 6 months of age and that this proliferative abnormality was corrected to the wild-type level by the double-transgene alleles until 9 months of age. In contrast, increased apoptosis was seen only in the 12-month-old $P k d 2^{--}: P K D 2^{\text {tg }}$ kidneys and was not recovered by the additional transgene allele. These results indicate that PC2 effects on kidney tubule cell proliferation plays a key role in cyst formation in ADPKD, although a role for apoptosis could not be completely excluded.

In addition, the late-stage mortality can be seen in $P k d 2$-null mice with hemizygous and homozygous $P K D 2$ transgene $\left(P k d 2^{-/-} ; P K D 2^{\mathrm{tg}}\right.$ and $\left.P k d 2^{-1-} ; P K D 2^{\mathrm{tg} / \mathrm{tg}}\right)$. The causes of the late-stage mortality in transgenically rescued animals are unclear. The relatively significant cystic disease seen in the $P k d 2$-null mice with hemizygous transgene $\left(P k d 2^{-/-} ; P K D 2^{\mathrm{tg}}\right)$ suggests a possible contribution from kidney failure, but this is unlikely to be the whole explanation and certainly would not explain the increased late-stage mortality observed in the $P k d 2$-null mice with homozygous $P K D 2$ transgene $\left(P k d 2^{-/-} ; P K D 2^{\mathrm{tg} / \mathrm{tg}}\right)$. However, a result of the current study (Figure 8, M-P) may imply a cue for the cause of late-stage mortality in $P k d 2^{-/-} ; P K D 2^{\mathrm{tg} / \mathrm{tg}}$ mice. Abnormally increased proliferation and apoptosis in the $P k d 2^{-1-} ; P K D 2^{\text {tg }}$ kidney were rectified down to wild-type level by homozygous $P K D 2$ transgene until age 9 months, but not 12 months, suggesting that ectopic PC2 expression might not fully rescue the cellular defects in the late-stage $P k d 2^{-/-} ; P K D 2^{\text {tg } / \mathrm{tg}}$ mouse. Beyond that, the transgenes may be partially silenced over time. These factors may account for the relatively sporadic appearance of late-stage cystic disease in the transgenically rescued null animals. Together with unrecovered proliferation and apoptosis in late-stage $P k d 2^{-/} ; P K D 2^{\text {tg/tg }}$ mice, similarly variegated transgene expression in other organs and cell types may contribute to the overall mortality in the late-stage rescued animals.

Cardiac heterotaxy associated with laterality defects have also been reported in $P k d 2$-null mice. ${ }^{21,32,33}$ To determine whether the ectopic expression of the human PKD2 transgene was able to eliminate these defects, we systematically examined the cardiac structure and axis of the left-right determination in the $P k d 2$-null mice with the PKD2 transgene. Our data revealed no such defects in the transgenic mice examined, and the finding that $\mathrm{PC} 2$ expression was indeed restored in cilia at the embryonic node of E7.5 $P k d 2^{-I-} ; P K D 2^{\text {tg }}$ mice supports the conclusion that the cardiac and laterality defects in the $P k d 2$-null mice are restored by functional expression of the human PKD2 transgene, most likely in the cilia of the embryonic node.

In summary, we have developed a new transgenic mouse line in which the overexpression of human $\mathrm{PC} 2$ was detected in the kidney, liver, and pancreas, which were all affected by ADPKD. In particular, this new PKD2-transgenic mouse line does not display obvious disease phenotypes on a wild-type background. Expression of the human PC2 fully rescued the embryonic lethality and cardiac defects in $P k d 2$-null mice, and markedly slowed the formation of cysts in the kidneys, liver, and pancreas in $P k d 2$-deficient mice, in a transgene-dosedependent manner. Using this model system, we also deduced that this beneficial effect results from reduced proliferation of cyst-prone epithelial cells in mouse models of ADPKD with $P k d 2$ inactivation (Table 1). These findings shed light on the 
use of gene transfer to treat ADPKD, for which no suitable therapy is currently available.

\section{Supplemental Data}

Supplemental material for this article can be found at http://dx.doi.org/10.1016/j.ajpath.2015.06.014.

\section{References}

1. Igarashi P, Somlo S: Genetics and pathogenesis of polycystic kidney disease. J Am Soc Nephrol 2002, 13:2384-2398

2. Fedeles SV, Gallagher AR, Somlo S: Polycystin-1: a master regulator of intersecting cystic pathways. Trends Mol Med 2014, 20:251-260

3. Torres VE, Harris PC: Autosomal dominant polycystic kidney disease: the last 3 years. Kidney Int 2009, 76:149-168

4. Gallagher AR, Germino GG, Somlo S: Molecular advances in autosomal dominant polycystic kidney disease. Adv Chronic Kidney Dis 2010, 17:118-130

5. Milutinovic J, Fialkow PJ, Rudd TG, Agodoa LY, Phillips LA, Bryant JI: Liver cysts in patients with autosomal dominant polycystic kidney disease. Am J Med 1980, 68:741-744

6. Spirli C, Okolicsanyi S, Fiorotto R, Fabris L, Cadamuro M, Lecchi S, Tian X, Somlo S, Strazzabosco M: Mammalian target of rapamycin regulates vascular endothelial growth factor-dependent liver cyst growth in polycystin-2-defective mice. Hepatology 2010, 51:1778-1788

7. Bae KT, Zhu F, Chapman AB, Torres VE, Grantham JJ, GuayWoodford LM, Baumgarten DA, King BF Jr, Wetzel LH, Kenney PJ, Brummer ME, Bennett WM, Klahr S, Meyers CM, Zhang X, Thompson PA, Miller JP: Magnetic resonance imaging evaluation of hepatic cysts in early autosomal-dominant polycystic kidney disease: the Consortium for Radiologic Imaging Studies of Polycystic Kidney Disease cohort. Clin J Am Soc Nephrol 2006, 1:64-69

8. Bae KT, Grantham JJ: Imaging for the prognosis of autosomal dominant polycystic kidney disease. Nat Rev Nephrol 2010, 6:96-106

9. Torra R, Nicolau C, Badenas C, Navarro S, Perez L, Estivill X, Darnell A: Ultrasonographic study of pancreatic cysts in autosomal dominant polycystic kidney disease. Clin Nephrol 1997, 47:19-22

10. Ong AC: Screening for intracranial aneurysms in ADPKD. BMJ 2009, 339:b3763

11. Torres VE, Pirson Y, Wiebers DO: Cerebral aneurysms. N Engl J Med 2006, 355:2703-2704. author reply 5

12. Adeola T, Adeleye O, Potts JL, Faulkner M, Oso A: Thoracic aortic dissection in a patient with autosomal dominant polycystic kidney disease. J Natl Med Assoc 2001, 93:282-287

13. Liu D, Wang CJ, Judge DP, Halushka MK, Ni J, Habashi JP, Moslehi J, Bedja D, Gabrielson KL, Xu H, Qian F, Huso D, Dietz HC, Germino GG, Watnick T: A Pkd1-Fbn1 Genetic Interaction Implicates TGF-beta Signaling in the Pathogenesis of Vascular Complications in Autosomal Dominant Polycystic Kidney Disease. J Am Soc Nephrol 2014, 25:81-91

14. Harris PC, Torres VE: Genetic mechanisms and signaling pathways in autosomal dominant polycystic kidney disease. J Clin Invest 2014, $124: 2315-2324$

15. Qian F, Watnick TJ, Onuchic LF, Germino GG: The molecular basis of focal cyst formation in human autosomal dominant polycystic kidney disease type I. Cell 1996, 87:979-987

16. Wu G, D’Agati V, Cai Y, Markowitz G, Park JH, Reynolds DM, Maeda Y, Le TC, Hou H Jr, Kucherlapati R, Edelmann W, Somlo S: Somatic inactivation of $\mathrm{Pkd} 2$ results in polycystic kidney disease. Cell 1998, 93:177-188

17. Piontek K, Menezes LF, Garcia-Gonzalez MA, Huso DL, Germino GG: A critical developmental switch defines the kinetics of kidney cyst formation after loss of Pkd1. Nat Med 2007, 13:1490-1495
18. Takakura A, Contrino L, Zhou X, Bonventre JV, Sun Y, Humphreys BD, Zhou J: Renal injury is a third hit promoting rapid development of adult polycystic kidney disease. Hum Mol Genet 2009, 18:2523-2531

19. Karihaloo A, Koraishy F, Huen SC, Lee Y, Merrick D, Caplan MJ, Somlo S, Cantley LG: Macrophages promote cyst growth in polycystic kidney disease. J Am Soc Nephrol 2011, 22:1809-1814

20. Hopp K, Ward CJ, Hommerding CJ, Nasr SH, Tuan HF, Gainullin VG, Rossetti S, Torres VE, Harris PC: Functional polycystin-1 dosage governs autosomal dominant polycystic kidney disease severity. J Clin Invest 2012, 122:4257-4273

21. Wu G, Markowitz GS, Li L, D’ Agati VD, Factor SM, Geng L, Tibara S, Tuchman J, Cai Y, Park JH, van Adelsberg J, Hou H Jr, Kucherlapati R, Edelmann W, Somlo S: Cardiac defects and renal failure in mice with targeted mutations in Pkd2. Nat Genet 2000, 24:75-78

22. Ikawa M, Kominami K, Yoshimura Y, Tanaka K, Nishimune $\mathrm{Y}$, Okabe M: A rapid and non-invasive selection of transgenic embryos before implantation using green fluorescent protein (GFP). FEBS Lett 1995, 375:125-128

23. Kim I, Ding T, Fu Y, Li C, Cui L, Li A, Lian P, Liang D, Wang DW, Guo C, Ma J, Zhao P, Coffey RJ, Zhan Q, Wu G: Conditional mutation of $\mathrm{Pkd} 2$ causes cystogenesis and upregulates beta-catenin. J Am Soc Nephrol 2009, 20:2556-2569

24. Kim I, Fu Y, Hui K, Moeckel G, Mai W, Li C, Liang D, Zhao P, Ma J, Chen XZ, George AL Jr, Coffey RJ, Feng ZP, Wu G: Fibrocystin/polyductin modulates renal tubular formation by regulating polycystin-2 expression and function. J Am Soc Nephrol 2008, 19:455-468

25. Zhang MZ, Mai W, Li C, Cho SY, Hao C, Moeckel G, Zhao R, Kim I, Wang J, Xiong H, Wang H, Sato Y, Wu Y, Nakanuma Y, Lilova M, Pei Y, Harris RC, Li S, Coffey RJ, Sun L, Wu D, Chen XZ, Breyer MD, Zhao ZJ, McKanna JA, Wu G: PKHD1 protein encoded by the gene for autosomal recessive polycystic kidney disease associates with basal bodies and primary cilia in renal epithelial cells. Proc Natl Acad Sci U S A 2004, 101:2311-2316

26. Park EY, Sung YH, Yang MH, Noh JY, Park SY, Lee TY, Yook YJ, Yoo KH, Roh KJ, Kim I, Hwang YH, Oh GT, Seong JK, Ahn C, Lee HW, Park JH: Cyst formation in kidney via B-Raf signaling in the PKD2 transgenic mice. J Biol Chem 2009, 284:7214-7222

27. Burtey S, Riera M, Ribe E, Pennekamp P, Passage E, Rance R, Dworniczak B, Fontes M: Overexpression of PKD2 in the mouse is associated with renal tubulopathy. Nephrol Dial Transplant 2008, 23: $1157-1165$

28. Wu G, Tian X, Nishimura S, Markowitz GS, D’Agati V, Park JH, Yao L, Li L, Geng L, Zhao H, Edelmann W, Somlo S: Trans-heterozygous Pkd1 and Pkd2 mutations modify expression of polycystic kidney disease. Hum Mol Genet 2002, 11:1845-1854

29. Dubois NC, Hofmann D, Kaloulis K, Bishop JM, Trumpp A: NestinCre transgenic mouse line Nes-Cre1 mediates highly efficient $\mathrm{Cre} /$ loxP mediated recombination in the nervous system, kidney, and somite-derived tissues. Genesis 2006, 44:355-360

30. Zimmerman L, Parr B, Lendahl U, Cunningham M, McKay R, Gavin B, Mann J, Vassileva G, McMahon A: Independent regulatory elements in the nestin gene direct transgene expression to neural stem cells or muscle precursors. Neuron 1994, 12:11-24

31. Shillingford JM, Piontek KB, Germino GG, Weimbs T: Rapamycin Ameliorates PKD Resulting from Conditional Inactivation of Pkd1. J Am Soc Nephrol 2010, 21:489-497

32. Pennekamp P, Karcher C, Fischer A, Schweickert A, Skryabin B, Horst J, Blum M, Dworniczak B: The ion channel polycystin-2 is required for left-right axis determination in mice. Curr Biol 2002, 12: 938-943

33. Yoshiba S, Shiratori H, Kuo IY, Kawasumi A, Shinohara K, Nonaka S, Asai Y, Sasaki G, Belo JA, Sasaki H, Nakai J, Dworniczak B, Ehrlich BE, Pennekamp P, Hamada H: Cilia at the node of mouse embryos sense fluid flow for left-right determination via Pkd2. Science 2012, 338:226-231 
34. McGrath J, Somlo S, Makova S, Tian X, Brueckner M: Two populations of node monocilia initiate left-right asymmetry in the mouse. Cell 2003, 114:61-73

35. Nadasdy T, Laszik Z, Lajoie G, Blick KE, Wheeler DE, Silva FG: Proliferative activity of cyst epithelium in human renal cystic diseases. J Am Soc Nephrol 1995, 5:1462-1468

36. Zhou XJ, Kukes G: Pathogenesis of autosomal dominant polycystic kidney disease: role of apoptosis. Diagn Mol Pathol 1998, 7:65-68

37. Takiar V, Caplan MJ: Polycystic kidney disease: pathogenesis and potential therapies. Biochim Biophys Acta 2011, 1812:1337-1343

38. Zhou X, Fan LX, Sweeney WE Jr, Denu JM, Avner ED, Li X: Sirtuin 1 inhibition delays cyst formation in autosomal-dominant polycystic kidney disease. J Clin Invest 2013, 123:3084-3098

39. Grantham JJ, Geiser JL, Evan AP: Cyst formation and growth in autosomal dominant polycystic kidney disease. Kidney Int 1987, 31 : 1145-1152

40. Boletta A, Qian F, Onuchic LF, Bhunia AK, Phakdeekitcharoen B, Hanaoka K, Guggino W, Monaco L, Germino GG: Polycystin-1, the gene product of PKD1, induces resistance to apoptosis and spontaneous tubulogenesis in MDCK cells. Mol Cell 2000, 6: $1267-1273$

41. Nishio S, Hatano M, Nagata M, Horie S, Koike T, Tokuhisa T, Mochizuki T: Pkd1 regulates immortalized proliferation of renal tubular epithelial cells through p53 induction and JNK activation. J Clin Invest 2005, 115:910-918

42. Chapin HC, Caplan MJ: The cell biology of polycystic kidney disease. J Cell Biol 2010, 191:701-710

43. Koupepidou P, Felekkis KN, Kranzlin B, Sticht C, Gretz N, Deltas C: Cyst formation in the PKD2 (1-703) transgenic rat precedes deregulation of proliferation-related pathways. BMC Nephrol 2010, 11:23

44. Kuo IY, DesRochers TM, Kimmerling EP, Nguyen L, Ehrlich BE, Kaplan DL: Cyst formation following disruption of intracellular calcium signaling. Proc Natl Acad Sci U S A 2014, 111:14283-14288

45. Shillingford JM, Murcia NS, Larson CH, Low SH, Hedgepeth R, Brown N, Flask CA, Novick AC, Goldfarb DA, Kramer-Zucker A, Walz G, Piontek KB, Germino GG, Weimbs T: The mTOR pathway is regulated by polycystin-1, and its inhibition reverses renal cystogenesis in polycystic kidney disease. Proc Natl Acad Sci U S A 2006, 103:5466-5471

46. Benzing T, Simons M, Walz G: Wnt signaling in polycystic kidney disease. J Am Soc Nephrol 2007, 18:1389-1398

47. Bello-Reuss E: Inhibition of tubule-cell proliferation to prevent cyst formation: a new avenue to treat ADPKD? Kidney Int 2007, 72 $135-137$

48. Song X, Di Giovanni V, He N, Wang K, Ingram A, Rosenblum ND, Pei Y: Systems biology of autosomal dominant polycystic kidney disease (ADPKD): computational identification of gene expression pathways and integrated regulatory networks. Hum Mol Genet 2009 , 18:2328-2343

49. Merrick D, Chapin H, Baggs JE, Yu Z, Somlo S, Sun Z, Hogenesch JB Caplan MJ: The gamma-secretase cleavage product of polycystin-1 regulates TCF and CHOP-mediated transcriptional activation through a p300-dependent mechanism. Dev Cell 2012, 22:197-210

50. Watnick TJ, Germino GG: Polycystic kidney disease: Polycystin-1 and polycystin-2-it's complicated. Nat Rev Nephrol 2013, 9: 249-250

51. Aguiari G, Catizone L, Del Senno L: Multidrug therapy for polycystic kidney disease: a review and perspective. Am J Nephrol 2013, 37: $175-182$

52. Baur BP, Meaney CJ: Review of Tolvaptan for Autosomal Dominant Polycystic Kidney Disease. Pharmacotherapy 2014, 34:605-616

53. Watnick T, Germino GG: mTOR inhibitors in polycystic kidney disease. N Engl J Med 2010, 363:879-881

54. Wu G, Mochizuki T, Le TC, Cai Y, Hayashi T, Reynolds DM, Somlo S: Molecular cloning, cDNA sequence analysis, and chromosomal localization of mouse Pkd2. Genomics 1997, 45:220-223

55. Pritchard L, Sloane-Stanley JA, Sharpe JA, Aspinwall R, Lu W, Buckle V, Strmecki L, Walker D, Ward CJ, Alpers CE, Zhou J, Wood WG, Harris PC: A human PKD1 transgene generates functional polycystin-1 in mice and is associated with a cystic phenotype. Hum Mol Genet 2000, 9:2617-2627

56. Thivierge C, Kurbegovic A, Couillard M, Guillaume R, Cote O, Trudel M: Overexpression of PKD1 causes polycystic kidney disease. Mol Cell Biol 2006, 26:1538-1548

57. Cai Y, Fedeles SV, Dong K, Anyatonwu G, Onoe T, Mitobe M, Gao JD, Okuhara D, Tian X, Gallagher AR, Tang Z, Xie X, Lalioti MD, Lee AH, Ehrlich BE, Somlo S: Altered trafficking and stability of polycystins underlie polycystic kidney disease. J Clin Invest 2014, 124:5129-5144

58. Shibazaki S, Yu Z, Nishio S, Tian X, Thomson RB, Mitobe M, Louvi A, Velazquez H, Ishibe S, Cantley LG, Igarashi P, Somlo S: Cyst formation and activation of the extracellular regulated kinase pathway after kidney specific inactivation of Pkd1. Hum Mol Genet 2008, 17:1505-1516

59. Fedeles SV, Tian X, Gallagher AR, Mitobe M, Nishio S, Lee SH, Cai Y, Geng L, Crews CM, Somlo S: A genetic interaction network of five genes for human polycystic kidney and liver diseases defines polycystin-1 as the central determinant of cyst formation. Nat Genet 2011, 43:639-647

60. Ma M, Tian X, Igarashi P, Pazour GJ, Somlo S: Loss of cilia suppresses cyst growth in genetic models of autosomal dominant polycystic kidney disease. Nat Genet 2013, 45:1004-1012 